OPEN ACCESS

Edited by:

Kulmira Nurgali,

Victoria University, Australia

Reviewed by:

Amit K. Tyagi,

University of Texas MD Anderson

Cancer Center, USA

Stefania Nobili,

University of Florence, Italy

*Correspondence:

Felipe Lombó

lombofelipe@uniovi.es

Specialty section:

This article was submitted to Pharmacology of Anti-Cancer Drugs,

a section of the journal

Frontiers in Pharmacology

Received: 15 November 2016

Accepted: 22 February 2017

Published: 14 March 2017

Citation:

Redondo-Blanco S, Fernández J,

Gutiérrez-del-Río I, Villar CJ and Lombó F (2017) New Insights toward

Colorectal Cancer Chemotherapy

Using Natural Bioactive Compounds.

Front. Pharmacol. 8:109.

doi: 10.3389/fphar.2017.00109

\section{New Insights toward Colorectal Cancer Chemotherapy Using Natural Bioactive Compounds}

\author{
Saúl Redondo-Blanco, Javier Fernández, Ignacio Gutiérrez-del-Río, Claudio J. Villar and \\ Felipe Lombó *
}

Departamento de Biología Funcional, Área de Microbiología, Facultad de Medicina, Instituto Universitario de Oncología del Principado de Asturias (IUOPA), Universidad de Oviedo, Oviedo, Spain

Combination therapy consists in the simultaneous administration of a conventional chemotherapy drug (or sometimes, a radiotherapy protocol) together with one or more natural bioactives (usually from plant or fungal origin) of small molecular weight. This combination of anticancer drugs may be applied to cell cultures of tumor cells, or to an animal model for a cancer type (or its xenograft), or to a clinical trial in patients. In this review, we summarize current knowledge describing diverse synergistic effects on colorectal cancer cell cultures, animal models, and clinical trials of various natural bioactives (stillbenes, flavonoids, terpenes, curcumin, and other structural families), which may be important with respect to diminish final doses of the chemotherapy drug, although maintaining its biological effect. This is important as these approaches may help reduce side effects in patients under conventional chemotherapy. Also, these molecules may exerts their synergistic effects via different cell cycle pathways, including different ones to those responsible of resistance phenotypes: transcription factors, membrane receptors, adhesion and structural molecules, cell cycle regulatory components, and apoptosis pathways.

Keywords: CRC, nutraceutical, chemotherapy, radiotherapy, combination therapy, apoptosis

\section{INTRODUCTION}

CRC is the third most common cancer in men (after lung and prostate cancers) and the second in women (after breast cancer) worldwide, with a prevalence of 10.0 and 9.2\%, respectively (Merrill and Anderson, 2011; Bray et al., 2013; Ferlay et al., 2015). CRC is also one of the leading death causes and, despite the improvement in our knowledge in this disease achieved in recent years, current treatments are not enough to control metastatic forms of CRC (Santandreu et al., 2011). Surgery is the main procedure in patients with potentially curable CRC, but neoadjuvant chemotherapy and/or radiotherapy is sometimes given before or after surgery depending on disease stage. However, these treatment regimens are not enough to control CRC, since $30 \%$ of patients with stage I-III and up to $65 \%$ of patients with stage IV will develop recurrent disease (van der Stok et al., 2016), highlighting the urgency of finding new and more effective treatment schemes.

The potential of nutraceutical natural compounds such as flavonoids, anthocyanidins, carotenoids, or terpenoids for cancer prevention has been widely investigated, and there are many evidences supporting that moderate consumption of fruits and vegetables is correlated with decreased risk of CRC (Fernández et al., 2016). Some members of these families of compounds have 
the ability to modulate signaling pathways as well as to regulate the expression of genes involved in cell cycle regulation, differentiation, and apoptosis (Pan et al., 2011). Besides being useful in prevention, some of these molecules could be also helpful for the treatment of CRC, especially in combination with other drugs.

Combination therapy allows targeting simultaneously different pathways involved in cancer, taking advantage of different mechanisms of action in order to reduce the development of tumor drug resistance (Housman et al., 2014). In the case of CRC, diverse cell cycle alterations are involved in its establishment and development, as in the case of chromosomal instability versions (CIN; around two-thirds of cases), the DNA mismatch repair phenotype (around $15 \%$ of CRC cases) and other less frequent CRC versions as abnormal DNA methylation, colon inflammation status, and microRNA triggering effects (Colussi et al., 2013). In CIN CRC phenotypes, for example, diverse signaling pathways become affected, as those involving APC, $\beta$-catenin, Tcf, and WNT proteins (Morin et al., 1997; Sparks et al., 1998). Several studies published in recent years have shown that cancer treatment through combinatorial approach is much more effective than the use of drugs individually (Singh et al., 2013). Also, chemosensitization by means of phytochemicals, based on the use of a natural compound to increase the activity of a drug through modulation of its resistance pathways, is one of the strategies proposed to overcome chemoresistance, one of the main challenges in CRC treatment (Amiri et al., 2013).

Combinations of two drugs onto a biological system may produce improved (synergistic), reduced (antagonistic), or identical (additive) effects compared to their effects when acting separately. Since combinatorial approach to cancer treatment with natural compounds is a promising way to avoid resistances (by affecting more than one target) and to enhance the potency of chemotherapy (through chemosensitization; Majumdar et al., 2009; Gupta et al., 2011), it is necessary for researchers to mathematically assess the nature of these interactions between molecules. This is often made by using the Chou-Talay combination index (CI), based on the median-effect equation: $C I=a / A+b / B$ (Chou and Talalay, 1984). $A$ and $B$ are, respectively, the doses of $\operatorname{drug} A$ (alone) and $B$ (alone) needed to produce a specified effect while $a$ and $b$ is the dose in combination that produces the same effect. CI shows an additive interaction between two drugs when it is equal to 1 , synergism when $\mathrm{CI}<1$, and antagonism when CI $>1$ (Tallarida, 2002).

\section{STILBENES}

Resveratrol (Figure 1A) is a stilbene found in more than 70 plant species, including edible plants such as grapes, raspberries, blueberries, or peanuts, and the Japanese knotweed (Polygonum cuspidatum), which contains the highest naturally occurring levels of this molecule (Burns et al., 2002). Resveratrol is a phytoalexin, a natural inhibitor of cell proliferation, synthesized by plants in response to environmental stress and pathogenic invasion (Singh et al., 2013).

Since the publication in 1997 of the chemopreventive activity of topically applied resveratrol in a mouse model of skin cancer (Jang et al., 1997), this natural compound has been extensively studied for the prevention and also treatment of many diseases, including CRC. The promising in vitro results of these studies have made resveratrol one of the natural compounds that have attracted more attention in recent times, even among mainstream media. For example, resveratrol can interfere with some hallmarks of cancer, protecting against both tumor initiation and cancer progression by interfering with cytochrome $\mathrm{P}_{450}$ isoenzymes, inhibiting cyclooxygenase (COX) enzymes and decreasing DNA binding activity of NF-kB, which is usually upregulated in cancer. Resveratrol can also mimic the effects of caloric restriction and protect against metabolic disease, through activation of the SIRT1 histone deacetylase and AMPK (Gescher et al., 2013; Carter et al., 2014).

Beyond its potential usefulness in cancer chemoprevention or even treatment, recent studies have shown that resveratrol can exert synergistic activities used in combination with other chemotherapeutic agents (Table 1). This would allow to establish a new and more effective treatment with fewer side effects (Singh et al., 2013). An overview of the studies published to date analyzing combinations of resveratrol with antitumor drugs is reviewed below.

Combinations of resveratrol and quercetin have been shown to synergistically induce apoptosis in the MOLT-4 leukemia cell line (Mertens-Talcott and Percival, 2005). Based on this study, the effects of different concentrations of a 1:1 combination of quercetin and resveratrol on the HT-29 CCR cell line were analyzed, focusing on its effect on Sp transcription factors, usually overexpressed in tumors. The combination of both compounds induced apoptosis in the HT-29 line, decreasing RNA and protein levels of survivin, Sp1, Sp3, and Sp4, in a pathway in which the microRNA-27a appears to be involved. It should be noted that in this study no synergistic effect can be detected between the two compounds since all the tests were carried out with combinations of both compounds and their effects alone were not analyzed (Del Follo-Martinez et al., 2013).

Using an azoxymethane-induced mouse model of colon carcinogenesis, recent studies showed that a combination of resveratrol and grape seed extract reduced the incidence of tumors as much as the nonsteroidal anti-inflammatory drug sulindac, without occurrence of toxicity. In addition, in vitro assays performed with isolated human colon cancer stem cells (CSCs) showed that this combination of compounds suppressed proliferation, sphere formation and nuclear translocation of $\beta$ catenin through the downregulation of $\mathrm{c}-\mathrm{Myc}$ and cyclin $\mathrm{D}$, downstream proteins of $\mathrm{Wnt} / \beta$-catenin pathway (Reddivari et al., 2016).

In 2004, it was discovered that resveratrol sensitizes HCT116 CRC cells to 5-Fluorouracil (5-FU; Fulda and Debatin, 2004). The first experiments were conducted in SHEP neuroblastoma cells, finding that resveratrol induces apoptosis in cooperation with several antitumor drugs (VP16, doxorubicin, cytarabine, actinomycin $\mathrm{D}$, taxol, or methotrexate). 


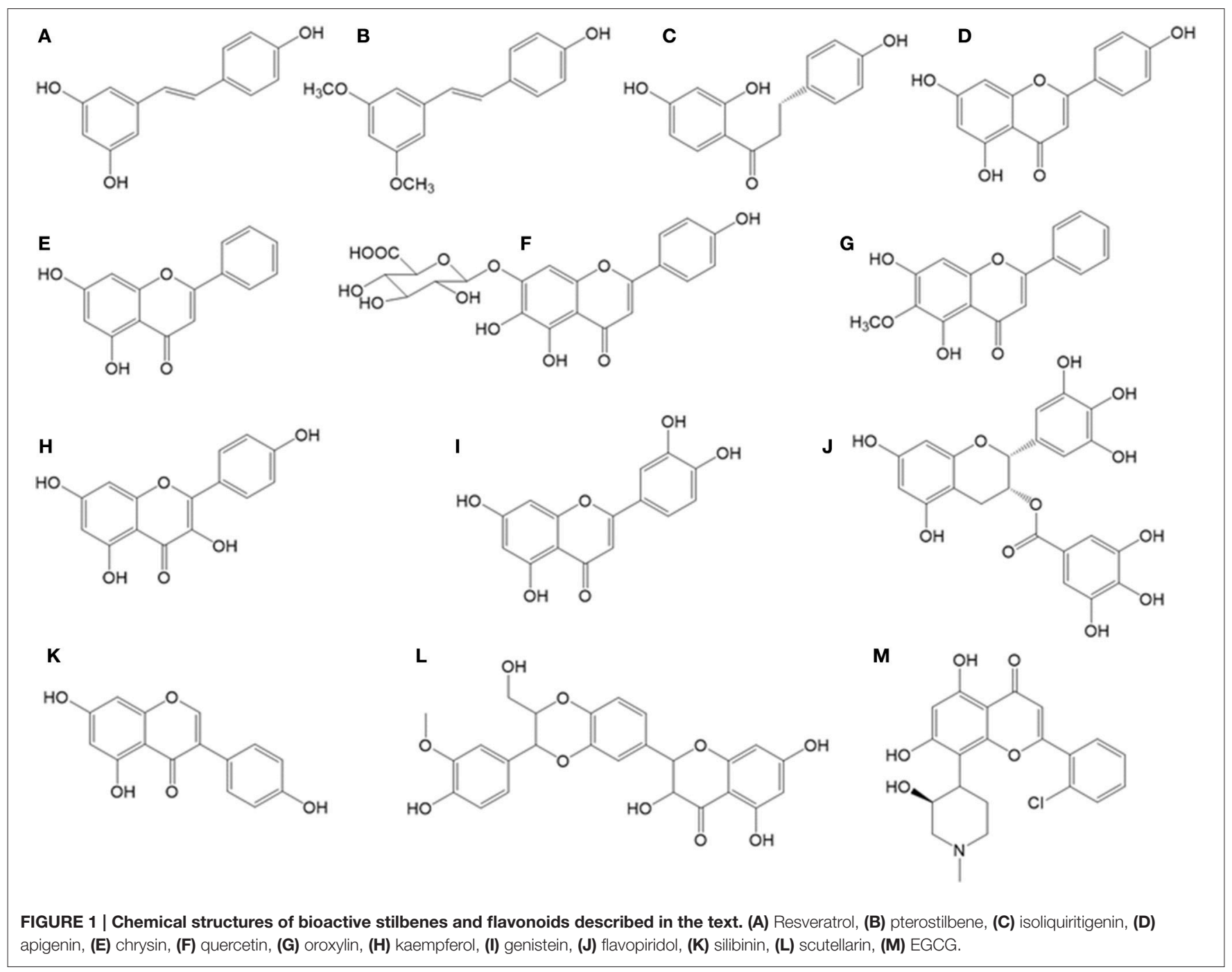

Interestingly, pretreatment with resveratrol prior to exposure of these antitumor drug was more effective than concurrent or subsequent treatment. In order to test the role of p53 in the chemosensitizing effect of resveratrol, additional experiments were performed with wild-type p53 and p53-deficient HCT116 CRC cells. Pretreatment with $30 \mu \mathrm{M}$ resveratrol for $24 \mathrm{~h}$ increased apoptosis induced by 5-FU (at 10, 30, and 100 $\mu \mathrm{M}$ during the next $24 \mathrm{~h}$ ) on both cell lines. These results suggest that resveratrol can induce cell cycle arrest and apoptosis independently of p53 status (Fulda and Debatin, 2004). Nevertheless, other researchers have reported that p53 upregulation could play an important role on the synergistic effect between resveratrol and etoposide, a topoisomerase II inhibitor used as an antineoplastic drug (Amiri et al., 2013).

Resveratrol also sensitizes HT-29 and SW620 CRC cell lines to cytotoxic oxidative stress induced by 5 -FU, by inhibiting their endogenous antioxidant capacity (Santandreu et al., 2011). Moderate resveratrol concentration $(15 \mu \mathrm{M})$ in combination with very low 5 -FU $(0.5 \mu \mathrm{M})$ concentration causes a significant inhibition of cell proliferation, migration, and cell cycle arrest at
S phase, leading to apoptosis in HCT-116 cells. The same study provides evidence suggesting that its mechanism of action may be related with the activation of the MAPK pathway through upregulation of $\mathrm{p}$-JNK and p-p38, with no p-ERK changes (Mohapatra et al., 2011). Similar results were found in a study with etoposide resistant HT-29 cells, where resveratrol was able to chemosensitize HT-29 cells promoting cell cycle inhibition, reactive oxygen species (ROS) generation, AMPK activation, and apoptosis induction (Hwang et al., 2007a).

Inter-cellular junctions could play an important role in the synergism observed between resveratrol and 5-FU, a drug which can induce an increase of mesenchymal features and loss of epithelial ones in CRC cells; those related to cancer proliferation, motility, drug resistance and metastasis. Resveratrol chemosensitizes CRC cells to 5-FU through inhibition of EMT (epithelial-mesenchymal transition) factors (vimentin and SNAI2 proteins), up-regulation of intercellular junctions (desmosomes, gap and tight junctions, and adhesion molecules such as E-cadherin) and by down-regulation of NF-kB pathway (Table 1; Buhrmann et al., 2015). 
TABLE 1 | Summary of main in vitro and in vivo synergistic effects of combinations of stilbenes and chemotherapeutic compounds against CRC.

\begin{tabular}{|c|c|c|c|c|c|}
\hline References & $\begin{array}{l}\text { Tested } \\
\text { molecule }\end{array}$ & $\begin{array}{l}\text { In combination } \\
\text { with }\end{array}$ & Experimental model & Main result & Proposed mechanism \\
\hline Ali and Braun, 2014 & Resveratrol & Mitomycin C & $\begin{array}{l}\text { CRC cell culture (primary } \\
\text { cell lines from resected } \\
\text { colorectal tumors) }\end{array}$ & $\begin{array}{l}\text { Synergistic suppression of cell } \\
\text { proliferation by resveratrol and } \\
\text { Mitomycin C }\end{array}$ & Up-regulation of $\mathrm{p} 21_{\mathrm{WAF} 1 / \mathrm{CIP} 1}$ \\
\hline Amiri et al., 2013 & Resveratrol & Etoposide & $\begin{array}{l}\text { CRC cell culture } \\
(\mathrm{HCT}-116)\end{array}$ & $\begin{array}{l}\text { Synergistic effect of resveratrol on } \\
\text { etoposide }\end{array}$ & $\begin{array}{l}\text { Up-regulation of TP53 } \\
\text { expression }\end{array}$ \\
\hline Buhrmann et al., 2015 & Resveratrol & 5-Flourouracil & $\begin{array}{l}\text { CRC cell culture } \\
\text { (HCT-116, SW480) in a } \\
\text { 3D-alginate } \\
\text { microenviroment }\end{array}$ & $\begin{array}{l}\text { Synergistic activity between } \\
\text { resveratrol and } 5 \text {-Fu decreasing } \\
\text { viability and inducing apoptosis }\end{array}$ & $\begin{array}{l}\text { Up-regulation of desmosomes, } \\
\text { gap and tight junction adhesion } \\
\text { molecules. Inhibition of EMT } \\
\text { factors. Down-regulation of } \\
\text { NF-kB activation }\end{array}$ \\
\hline Kaminski et al., 2014 & Resveratrol & Oxaliplatin & CRC cell culture (Caco-2) & $\begin{array}{l}\text { Positive: CRC cells } \\
\text { chemosensitization by resveratrol. } \\
\text { Synergistic activity of resveratrol } \\
\text { and oxaliplatin inhibiting CRC cell } \\
\text { growth }\end{array}$ & Induction of cell death \\
\hline Kumazaki et al., 2013 & Resveratrol & 5-Fluorouracil & $\begin{array}{l}\text { CRC cell culture (DLD-1, } \\
\text { SW480, COLO201) }\end{array}$ & $\begin{array}{l}\text { Synergistic enhancement of } \\
\text { growth inhibition and apoptosis }\end{array}$ & $\begin{array}{l}\text { Up-regulation of miR-34a } \\
\text { expression causing a } \\
\text { down-regulation of E2F3 }\end{array}$ \\
\hline Majumdar et al., 2009 & Resveratrol & Curcumin & $\begin{array}{l}\text { CRC cell culture } \\
\text { (HCT-116) and mouse } \\
\text { xenograft CRC models }\end{array}$ & $\begin{array}{l}\text { Synergism between curcumin and } \\
\text { resveratrol inhibiting growth of } \\
\text { CRC cells in vitro and in vivo }\end{array}$ & $\begin{array}{l}\text { Attenuation of NF-кB activity. } \\
\text { Inhibition of constitutive } \\
\text { activation of EGFR }\end{array}$ \\
\hline Mohapatra et al., 2011 & Resveratrol & 5-Fluorouracil & $\begin{array}{l}\text { CRC cell culture } \\
(\mathrm{HCT}-116)\end{array}$ & Synergistic induction of apoptosis & $\begin{array}{l}\text { Cell cycle arrest in S phase, } \\
\text { enhanced DNA damage }\end{array}$ \\
\hline Santandreu et al., 2011 & Resveratrol & 5-Fluorouracil & $\begin{array}{l}\text { CRC cell culture (HT-29, } \\
\text { SW620) }\end{array}$ & $\begin{array}{l}\text { Positive: Resveratrol sensitize CCR } \\
\text { cells to 5-Fluorouracil }\end{array}$ & $\begin{array}{l}\text { Increase in oxidative stress, } \\
\text { inactivation or down-regulation } \\
\text { of redox-sensitive proteins }\end{array}$ \\
\hline Yang S. et al., 2015 & Resveratrol & Oxaliplatin & $\begin{array}{l}\text { CRC cell culture } \\
(\mathrm{HCT}-116, \mathrm{HT}-29) \text { and } \\
\text { mouse xenograft CRC } \\
\text { model }\end{array}$ & $\begin{array}{l}\text { Synergistic effect of resveratrol and } \\
\text { oxaliplatin in a miR-34c dependent } \\
\text { manner }\end{array}$ & Up-regulation of miR-34c \\
\hline Fulda and Debatin, 2004 & Resveratrol & 5-Fluorouracil & $\begin{array}{l}\text { CRC cell culture } \\
(\mathrm{HCT}-116) \text { and other } \\
\text { human cancer cell lines }\end{array}$ & $\begin{array}{l}\text { Positive: Resveratrol sensitizes } \\
\text { CRC cells for subsequent } \\
\text { treatment with } 5-\mathrm{Fu}\end{array}$ & $\begin{array}{l}\text { Cell cycle arrest and apoptosis } \\
\text { by downregulation of surviving, } \\
\text { irrespective of p53 status }\end{array}$ \\
\hline Hwang et al., 2007a & Resveratrol & Etoposide & CRC cell culture (HT-29) & $\begin{array}{l}\text { Positive: Resveratrol } \\
\text { chemosensitizes CRC cells for } \\
\text { subsequent treatment with } \\
\text { etoposide }\end{array}$ & $\begin{array}{l}\text { inhibition of cell growth, } \\
\text { increase of ROS generation, } \\
\text { activation of AMPK, induction } \\
\text { of apoptosis }\end{array}$ \\
\hline $\begin{array}{l}\text { Tolba and } \\
\text { Abdel-Rahman, } 2015\end{array}$ & Pterostilbene & 5-Fluorouracil & $\begin{array}{l}\text { CRC cell culture } \\
\text { (HCT-116, Caco-2) }\end{array}$ & $\begin{array}{l}\text { Synergistic effect of pterostilbene } \\
\text { on cytotoxic effects of } 5 \text {-FU }\end{array}$ & $\begin{array}{l}\text { Supression of Akt and ERK } \\
\text { phosphorylation. Increase of } \\
\text { FOXO-1 and p27kip1 levels }\end{array}$ \\
\hline
\end{tabular}

A new mechanism based on miR-34a has been also described which may partially explain the synergistic inhibition of HCT116 growth induced by resveratrol and 5-FU. Here, resveratrol promoted suppression of PI3K/Akt and MAPK Erk1/2 signaling pathways and upregulation of miR-34a expression, which downregulates E2F3 gene expression and its downstream target Sirt1 gene (Kumazaki et al., 2013).

Other recent study shows that resveratrol chemosensitizes HT-29 and HCT-116 CRC cells to oxaliplatin through upregulation of miR-34c, which in turn knocked down its target KITLG. This result was confirmed in xenograft mice, where the combination treatment with oxaliplatin and resveratrol was more effective inhibiting tumor growth than individual treatments (Yang S. et al., 2015). Also, resveratrol and oxaliplatin combinations synergistically inhibit cell growth of Caco-2 CRC cells via apoptosis and necrosis induction (Kaminski et al., 2014).

Mitomycin $\mathrm{C}$ is another drug that can be potentially enhanced by resveratrol. Unlike mitomycin $\mathrm{C}$, resveratrol can induce $\mathrm{p} 21^{\mathrm{WAF} 1 / \mathrm{CIP} 1}$ overexpression regardless of p53 status, and a combined treatment of these two compounds has inhibited synergistically the proliferation of mitomycin C-resistant CRC cells (Ali and Braun, 2014).

Pterostilbene (Figure 1B), a structural analog to resveratrol, characterized by the presence of two methoxy groups instead of resveratrol hydroxyl groups, is able to enhance 5-FU treatment in CRC cells. This synergistic effect is stronger in Caco- 2 cells, which express higher levels of ER- $\beta$ (estrogen receptor beta) compared with HCT116 cells (Tolba and Abdel-Rahman, 2015). 
Despite all these promising features of resveratrol as chemopreventive, chemotherapeutic and chemosensitizer agent, clinical trials and other in vivo evidences suggest that there may be limitations in clinical application, mainly due to its low systemic availability. Between 70 and $80 \%$ of orally consumed resveratrol is quickly absorbed via passive diffusion in the enterocytes. After that, conjugated resveratrol derivatives (glucuronides and sulfates) are rapidly formed, and only $2 \%$ of unmodified trans-resveratrol is found in the blood, reaching its maximum concentration between 30 and $60 \mathrm{~min}$ after ingestion (Carter et al., 2014). For example, a single $25 \mathrm{mg}$ dose of resveratrol results in a $2 \mathrm{mM}(490 \mathrm{ng} / \mathrm{mL})$ serum peak for resveratrol and all of its metabolites, with only trace amounts of unmodified resveratrol $(<5 \mathrm{ng} / \mathrm{mL}$; Walle et al., 2004). Furthermore, it has been observed that resveratrol absorption and pharmacokinetics are strongly influenced by food matrix (Rotches-Ribalta et al., 2012) and by its metabolism by gastrointestinal microbiota (Bode et al., 2013). Also, resveratrol dosage in patients and volunteers over $1 \mathrm{~g}$ per day has shown gastrointestinal adverse effects such as diarrhea, flatulence, nausea, and abdominal pain (Brown et al., 2010). Anyway, resveratrol and its metabolites have been identified in normal and tumor colorectal human tissue samples, in higher concentrations than those found in blood samples after intake doses of $0.5-1 \mathrm{~g} /$ day. Thus, colorectum is a suitable target tissue for chemoprevention and combination therapy by oral resveratrol, as observed concentrations in this tissue are able to produce pharmacological effects (Patel et al., 2010).

\section{FLAVONOIDS}

Flavonoids are one of the most numerous and widely distributed family of bioactive compounds in plants. These polyphenolic secondary metabolites are essential for plants morphology and physiology. Flavonoids are involved in flowers, seeds, stems, and leaves pigmentation, as well as in its growth and reproduction (to attract pollinators), while at the same time they protect plants against microbial infections and ultraviolet radiation (Harborne and Williams, 2000). Chemically, flavonoids are characterized by showing a 15-C skeleton (structured as C6C3-C6) with two phenyl aromatic rings (A and B) plus one heterocycle aromatic ring (ring $\mathrm{C}$ ), all of them tailored with one or more hydroxyl groups (Manach et al., 2004). Flavonoids are further subdivided into several subgroups depending on the degree of substitution: chalcones (as isoliquiritigenin); flavanones (as naringenin), flavones (as apigenin and luteolin), flavonols (as quercetin and kaempferol), flavanols (as epigallocatechin), isoflavones (as genistein), and anthocyanins. Flavonoids are the largest group of diet polyphenols, with more than 4,000 representatives (Manach et al., 2004; Kumar and Pandey, 2007).

Although, flavonoids are not necessary nutrients for wellbeing in the short-term, there are several evidences that claim that a moderate intake has beneficial long-term health effects. These compounds, the same as stilbenes, are powerful antioxidants that prevent the appearance of tumors, cardiovascular diseases and osteoporosis, improve cognitive functions and diabetes; or have phytoestrogenic, anti-inflammatory, antibacterial, or antiviral actions, having therefore a strong impact on human health (Kumar and Pandey, 2013).

\section{Isoliquiritigenin}

Isoliquiritigenin (Figure 1C), a chalcone originated from dried roots of several Glycyrrhiza species (licorice plants), exhibits antioxidant, estrogenic, and anti-tumor activities (Guo et al., 2008). It has shown synergistic effect in combination with cisplatin in a xenograft mice model for CRC using CT-26 mouse CRC cells. In this mice model, an oral dose of $1 \mathrm{mg} / \mathrm{kg}$ of this chalcone, plus an intraperitoneal cisplatin injection of $5 \mathrm{mg} / \mathrm{kg}$ were able to reduce $79 \%$ the tumor growth. Also, addition of isoliquiritigenin to this cisplatin treatment was able to reduce liver and kidney damage, as transaminases (AST, ALT), creatinine and blood urea nitrogen levels were kept at normal concentrations, in contrast with control cisplatin treatment. With respect to oxidative damage, this combination therapy with isoliquiritigenin reduced nitric oxide serum levels, lipid peroxidation and GSH levels, in contrast to cisplatin treatment alone (Table 2; Lee et al., 2008). This point is very interesting, as major hepatic damages caused by cisplatin are bound to increased oxidative damage due to depletion in GSH levels and an increase in malonaldehyde and membrane peroxidation. Cisplatin treatment is also associated to increased serum levels of transaminases and bilirubin, two important markers for hepatic damage, following histopathological changes as necrosis and hepatocytes degeneration with infiltration of inflammatory cells around portal vein (Caro and Cederbaum, 2004; Dasari and Tchounwou, 2014). Increased liver damage due to cisplatin has been observed in patients with higher expression levels of cytochrome P450-2E1 (Caro and Cederbaum, 2004). The reduction achieved in cisplatin doses, if transferred to in vivo experiments, would contribute to a potential reduction in side effects caused by this drug, which usually are associated to ototoxicity, gastrotoxicity, myelosuppression, hepatotoxicity (due to ROS causing a reduction in GSH levels and an increase in malonaldehyde), cardiotoxicity (due to depletion in cardiac myocytes of lactate dehydrogenase and creatine kinase, following membrane peroxidation in these cells), and nephrotoxicity (due to inhibition of carnitine synthesis and its reabsorption by the proximal tube; Dasari and Tchounwou, 2014)(Figure 3).

\section{Apigenin}

Apigenin (Figure 1D) is one of the most widely distributed flavones in fruits and vegetables, such as parsley, Chinese cabbage, bell pepper, garlic, celery, and guava (Manach et al., 2004). It is a chemopreventive agent that has been shown to present strong cytostatic and anti-angiogenic effects in vitro (Hirano et al., 1989; Engelmann et al., 2002). In vitro, apigenin induces growth inhibition, cell cycle arrest, and apoptosis in CRC cells (Zhong et al., 2010; Lee Y. et al., 2014; Yang L. et al., 2015). Moreover, apigenin is a strong inhibitor of $\mathrm{ABC}$ transporters (ATP-Binding Cassette), which are responsible for the increase in the efflux of chemotherapeutic drugs in the lumen (apical) face of colonocytes, thereby significantly reducing its bioavailability and leading to its active detoxification (Katayama et al., 2007). Finally, 
TABLE 2 | Summary of main in vitro and in vivo synergistic effects of combinations of flavonoids and chemotherapeutic compounds against CRC.

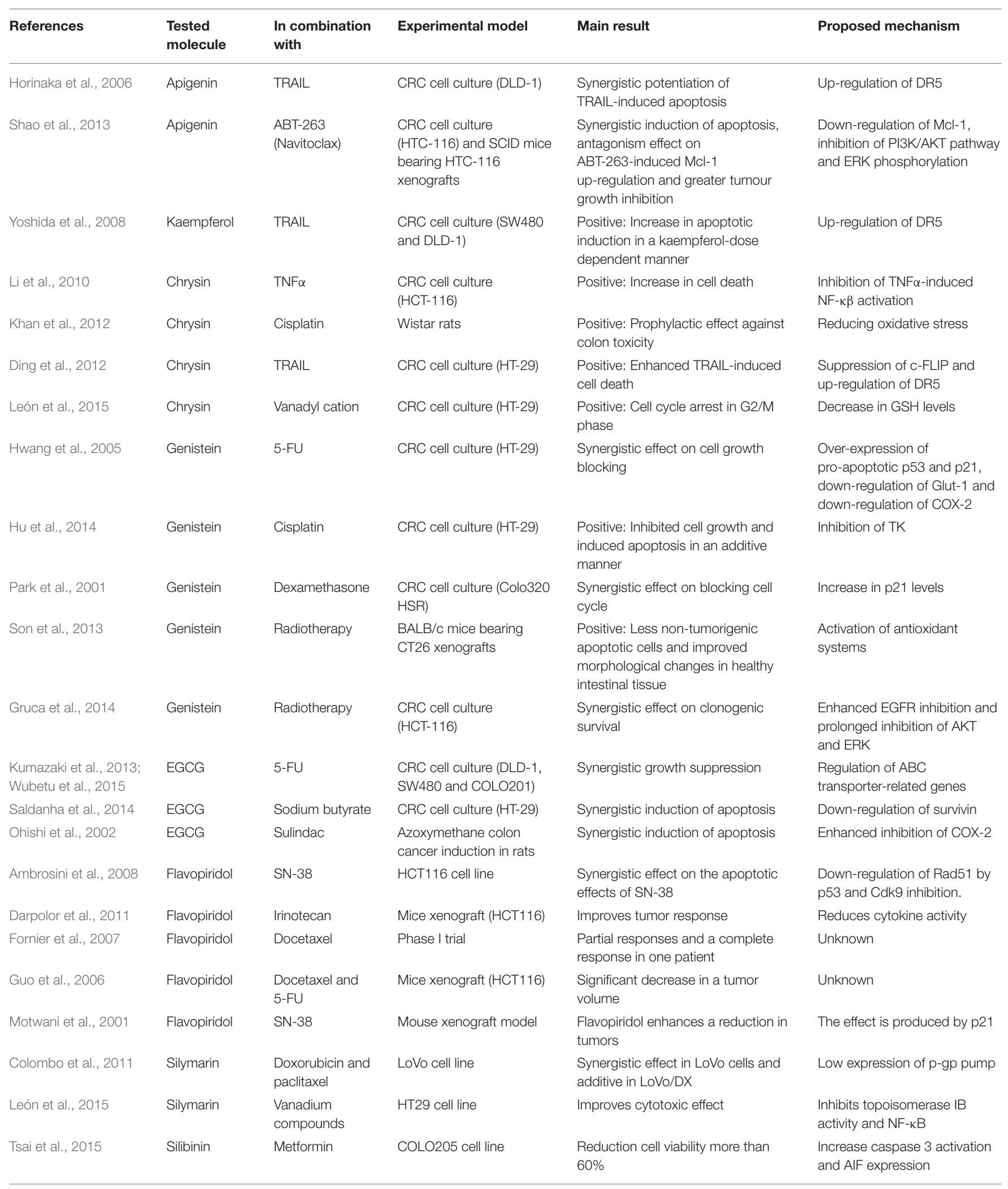


TABLE 2 | Continued

\begin{tabular}{|c|c|c|c|c|c|}
\hline References & $\begin{array}{l}\text { Tested } \\
\text { molecule }\end{array}$ & $\begin{array}{l}\text { In combination } \\
\text { with }\end{array}$ & Experimental model & Main result & Proposed mechanism \\
\hline Psahoulia et al., 2007 & Quercetin & TRAIL & $\begin{array}{l}\text { Caco- } 2 \text {, SW620 and } \\
\text { HT29 cell lines }\end{array}$ & Sensitizes the cells to the treatment & $\begin{array}{l}\text { Distribution of death factors in } \\
\text { raft domains that are the } \\
\text { initiators of apoptosis }\end{array}$ \\
\hline Xavier et al., 2011 & Quercetin & $5-\mathrm{FU}$ & $\begin{array}{l}\text { Co115 and HCT15 cell } \\
\text { lines }\end{array}$ & $\begin{array}{l}\text { Enhances apoptosis more than } 100 \\
\text { times }\end{array}$ & The effect is mediated by p53 \\
\hline Osman et al., 2015 & Luteolin & Aspirin & Colorectal cancer in rats & $\begin{array}{l}\text { Highly significant reduction in polyps } \\
\text { number and size }\end{array}$ & $\begin{array}{l}\text { Enhance inhibition the } \\
\text { inflammatory response }\end{array}$ \\
\hline Chan et al., 2009 & Scutellarin & $5-\mathrm{FU}$ & HCT116 cell line & $\begin{array}{l}\text { A significant increase in apoptosis } \\
\text { levels }\end{array}$ & $\begin{array}{l}\text { p53-regulated caspase- } 6 \\
\text { activation mechanism }\end{array}$ \\
\hline Lee et al., 2008 & Isoliquiritigenin & Cisplatin & Mice xenograft (CT26) & $\begin{array}{l}\text { Reduce } 79 \% \text { tumor growth and } \\
\text { reduces adverse effects }\end{array}$ & $\begin{array}{l}\text { Mechanism in combination is } \\
\text { unknown }\end{array}$ \\
\hline Ha et al., 2012 & Oroxylin & $5-\mathrm{FU}$ & $\begin{array}{l}\text { HT29 cell line and mice } \\
\text { xenografts (HT29) }\end{array}$ & $\begin{array}{l}\text { Reduce } 66 \% \text { tumor growth and } \\
\text { shows synergistic effects in HT29 } \\
\text { cell line }\end{array}$ & $\begin{array}{l}\text { Inhibition of COX-2 gene } \\
\text { expression }\end{array}$ \\
\hline Cheah et al., 2014 & Procyanidins & $5-F U$ & Caco-2 cell line & Increase cytotoxicity & Unknown \\
\hline
\end{tabular}

apigenin is also responsible for NAG-1 [Nonsteroidal Antiinflammatory Drug (NSAID) Activated Gene-1] overexpression in CRC cells, a member of the TGF-B (Transforming Growth Factor-B) superfamily which shows pro-apoptotic and antitumor activities (Yang et al., 2014). In fact, apigenin increases in a dose-dependent way in CRC cells, both in vivo and in vitro, NAG-1 and p53 expression, reducing intestinal tumor load and number (Zhong et al., 2010). Therefore, apigenin has a promising application as a safe antitumor agent. However, it has a modest antitumor activity against cancer cells when used alone, so new strategies are needed in order to enhance its effectiveness, as those based on combination therapy of this flavonoid with CRC drugs.

CD26 is a multifunctional cell-surface protein that is involved in the suppression of pathways responsible for tumor growth and metastasis. In fact, CD26 is down-regulated in several types of tumors including colon cancer and this protein is normally expressed in the epithelial cells of the human colon. Therefore, compounds which enhance CD26 levels are expected to have antitumor potential.

It has been shown that apigenin alone is able to cause an increase of $56.3 \%$ in the cell surface abundance and activity of CD26 in different CRC cell lines (HT-29 and HRT-18), so some authors have studied whether this flavone is able to enhance the up-regulation in CD26 cell surface expression of irinotecan, 5-FU and oxaliplatin, that are three chemotherapeutic agents used for the treatment of colorectal cancer. In the case of 5-FU and oxaliplatin, no specific interaction was reported with the action of apigenin; however, the ability of apigenin to potentiate CD26 was much more robust when was combined with increasing concentrations of irinotecan, generating a 4.2fold increase in the potency of this drug (with a reduction of $\mathrm{EC}_{50}$ for irinotecan from 4.68 to $1.26 \mu \mathrm{g} / \mathrm{mL}$ ). An interaction was also observed when the experimental design was reversed, adding a fixed dose of irinotecan to a series of apigenin concentrations, increasing by 30 times the capacity of apigenin to enhance CD26 expression, lowering its $\mathrm{EC}_{50}$ from 32.8 to $1.10 \mu \mathrm{M}$. Therefore, it was observed that in the case of irinotecan (a topoisomerase I inhibitor), but not of 5-FU or oxaliplatin, there is a specific interaction with the action of apigenin due to a cross-talk in the mechanism of action of apigenin with irinotecan, as apigenin is able to inhibit toposimorease I-DNA complex which overlaps with the primary mechanism of action of irinotecan (Lefort and Blay, 2011). This presupposes that part of the mechanism of action of apigenin is intimately related to topoisomerases.

TRAIL (tumor necrosis factor-related apoptosis-inducing protein), a member of the TNF superfamily, is able to induce apoptosis through interaction with the death receptor 5 (DR5), whose expression is regulated by the tumor suppressor p53. TRAIL is not toxic in normal cells because non-neoplastic cells express high levels of decoy receptors (DcR) for TRAIL, which could interfere with TRAIL signaling; it shows acquired resistance in cancer cells (Almasan and Ashkenazi, 2003; Du et al., 2016).

Apigenin induces the expression of DR5 in a dose-dependent manner preventing the degradation of this protein by acting as a proteasome inhibitor and increasing its expression in the membrane, so this up-regulation of DR5 acts in a synergic form sensitizing to the treatment with exogenous soluble recombinant human tumor necrosis factor-related apoptosis-inducing ligand (TRAIL) in CRC DLD-1 cells, showing a greater apoptotic effect than the treatment with TRAIL alone. As said before, TRAIL is an attractive candidate for cancer therapy because it selectively induces apoptosis in cancer cells, and it has been shown that combination of TRAIL with apigenin did not induce expression of DR5 protein and enhanced TRAIL-induced apoptosis in normal human PBMCs cells (Horinaka et al., 2006). Therefore, the combined treatment of apigenin and TRAIL is a promising anticancer therapy.

Diverse anti-apoptotic proteins as Bcl-XL, Bcl-2, Bcl-w, and Mcl-1 can prevent cell death in tumor cells. ABT-263 (Navitoclax) is a novel oral inhibitor for Bcl-2 family proteins, acting as a Bcl-2 homology 3 (BH3) mimetic, and leading to apoptosis, except in 
tumor cells with Mcl-1 overexpression (Tolcher et al., 2015). As apigenin induces apoptosis in tumor cells by modulating different kinds of signaling pathways, including downregulation of Mcl1 mRNA (Shi et al., 2015), this apigenin Mcl-1 downregulation may enhance the ABT-263 antitumor activity (Shao et al., 2013; Erdogan et al., 2016). Furthermore, the inhibitory effect of apigenin on ERK phosphorylation levels is significant when CRC HCT116 cells are cotreated with ABT-263 (Shao et al., 2013). All these findings were verified in vivo in a SCID mice model bearing HCT116 xenografts, in which treatment with ABT263 or apigenin alone resulted in a $30 \%$ inhibition of tumor growth compared with untreated control, but this percentage was increased to $70 \%$ by combination therapy, with decreased Mcl-1 levels as well as phosphorylated prosurvival mediators ERK or AKT (Table 2; Shao et al., 2013).

Summing up, both apigenin and ABT-263 alone induced low apoptosis rates in HCT116, DLS1, SW48, HT29, and HCT-8 tumor cells, but in combination therapy, an increase of $80 \%$ in apoptosis was recorded via a caspase dependent mechanism. The combination index of these combinations was below 1.0, indicating a synergistic effect (Shao et al., 2013).

\section{Chrysin}

Chrysin (Figure 1E) is another flavone found in honey, propolis, and various plant extracts such as chamomile and blue passion flower (Passiflora caerulea; Renuka et al., 2016). Chrysin has multiple biological activities, including antitumor effects in diverse cancer cell lines and tumor animal models (Kasala et al., 2015).

Several studies in SW480 CRC cells have shown that this flavone is able to induce cell cycle arrest at G2/M transition in a dose-dependent manner. Combination of chrysin plus apigenin doubled the proportion of SW480 cells in G2/M arrest; indicating that both flavones cooperate in slowing down tumor progression (Wang et al., 2004). In vitro studies on DLD1 CRC cells have demonstrated a chemoprotective effect of chrysin due to induction of AhR activity (Aryl Hydrocarbon Receptor) accompanied by p21 overexpression, a cell cycle important inhibitor (Ronnekleiv-Kelly et al., 2012). At early tumorigenesis stages, chrysin shows a chemopreventive activity by modulating normal cryptal cells proliferation and by activating apoptosis in aberrant cryptal cells (as those generated in an azoxymethane animal model for CRC). These activities are carried out by downregulating PCNA (Proliferating Cell Nuclear Antigen) and growth factors such as IGF-1 (Miyamoto et al., 2006, 2010; Kasala et al., 2015).

Tumor necrosis factor-alpha (TNF- $\alpha$ ) is a pro-inflammatory cytokine with a wide range of biological activities also including both cell progression and death. These TNF $\alpha$ conflicting activities rely on TNF receptor 1 (TNFR1) activation of two different pathways: a caspase cascade for induction of apoptotic events, and nuclear transcription factor kappa- $\beta$ (NF-k $\beta$ ), which is a cell survival mechanism. Generally, most tumor cells are refractory to $\mathrm{TNF} \alpha$-induced apoptosis if they keep a working NF-k $\beta$ pathway (Chen and Goeddel, 2002; Karin et al., 2004). But chrysin sensitizes HCT116 CRC cells (highly resistant to $\mathrm{TNF} \alpha$ apoptosis induction) toward $\mathrm{TNF} \alpha$-induced apoptosis due to its blocking of NF-k $\beta$ /caspase 8 pathway, by downregulating its trigger, c-FLIP-I (Li et al., 2010). Combination therapy with chrysin and TNF $\alpha$ together showed a $40 \%$ increase in cell death compared to monotherapy, due to caspase 8 activation (Table 2; Chen et al., 2004; Romier et al., 2008; Li et al., 2010).

TRAIL binding to death receptors as DR5 results in adaptor protein FADD (Fas-associated protein with death domain) and procaspase 8 or 10 recruitment, which then activate this death pathway. The main negative regulator of this pathway is the cellular caspase-8 (FLICE) inhibitory protein (c-FLIP). Its overexpression causes resistance to this apoptotic process, thereby limiting the therapeutic use of TRAIL. In order to overcome these resistances, a combination with TRAIL pathway sensitizers targeting c-FLIP expression may be a promising approach. In this sense, chrysin is able to suppress c-FLIP expression and to enhance DR5 expression in HT-29 cells, enhancing TRAIL-induced cell death in CRC cells (Ding et al., 2012).

Flavonoids antioxidant activity can also reduce chemotherapy side effects. Cisplatin generates a wide variety of ROS that interact with DNA, lipids, and proteins in CRC cells, including PtDNA adducts that hinder cell division and DNA synthesis/repair, leading to apoptotic events (Dasari and Tchounwou, 2014). In this sense, the prophylactic effect of chrysin against colon toxicity due to cisplatin was tested in Wistar rats, confirming a protective effect by reducing oxidative stress (Khan et al., 2012). Although, cisplatin is not used in CRC patients' treatment, these experiments in rats show interesting effects of chrysin with respect to ROS inducing agents.

With a similar action to cisplatin, vanadium compounds are considered a new class of non-platinum metal compounds with eventual low toxicity, although they are not used in clinical praxis. In vitro, these compounds inhibit cell cycle even at low doses, by generating ROS, which leads to DNA cleavage and apoptosis. Chrysin complexation with vanadyl cation increased antitumor activity in HT-29 cells (cell cycle arrest in G2/M transition) compared to the monotherapy treatment. Chrysin vanadate complex reduced to $56 \%$ the HT-29 cell survival vs. $88 \%$ in the case of cisplatin. This chrysin potentiating effect may be due to a reduction in GSH levels, one of the most important antioxidant defenses in mammals (León et al., 2015). In order to avoid gastrointestinal damage in preclinical trials, different vanadium complexes have been generated with flavonoids (Evangelou, 2002).

\section{Scutellarin}

Scutellarin is a glycoside of the flavone scutellarein (Figure 1F), isolated from the traditional Chinese medicine plant Scutellaria barbata (Xing et al., 2011). It has been used in HCT116 cells as chemosensitizing agent (at $100 \mu \mathrm{M}$ ) combined with resveratrol (at $200 \mu \mathrm{M}$ ) and 5-FU (at $500 \mu \mathrm{M}$ ). These experiments showed an increase in apoptosis, due co caspase 6 activation, which was absent in p53 (-/-) versions of this cell line (Chan et al., 2009).

\section{Oroxylin}

Oroxylin A is a O-methylated flavone (Figure 1G) extracted from the herb Scutellariae radix. Oroxylin A inhibits iNOS and COX-2 
gene expression by blocking NF- $\mathrm{B}$. Also, this flavone inhibits LPS-induced NF-kB activation by blocking I $\mathrm{B}$ degradation, the protein which usually binds NF-kB in the cytosol, keeping it in its inactive form (Chen et al., 2000).

Combination of oroxylin A with 5-FU (1:5) both in vivo and ex vivo in a CRC model using HT-29 cells showed a synergistic action, with COX-2 inhibition and increased ROS generation, which led to HT-20 sensitization to 5-FU. 5-FU IC $_{50}$ in HT29 is $4.63 \mathrm{mmol} / \mathrm{L}$, but when combined with oroxylin $\mathrm{A}$, this value diminishes to $764 \mu \mathrm{mol} / \mathrm{L}$. To corroborate this synergistic effect, in a nude mice xenograft model for HT-29, $100 \mathrm{mg} / \mathrm{kg}$ oroxylin A plus $20 \mathrm{mg} / \mathrm{kg} 5-\mathrm{FU}$ showed a $66 \%$ tumor size decrease, in comparison with 36 and $42 \%$ reduction in the monotherapies, respectively (Table 2; Ha et al., 2012). Therefore, oroxylin combination therapy could be a valuable tool in order to reduce 5-FU doses and subsequent in vivo side effects.

\section{Kaempferol}

Kaempferol (Figure 1H) is a flavonol present in black tea, broccoli, propolis, grapefruit, and other plant sources. This compound has a marked antitumor potential on different types of cancer cells (Gutiérrez-del-Río et al., 2016). In CRC cells, it induces p53-dependent growth inhibition and, at the same time, apoptosis by inducing cytochrome $\mathrm{c}$ mitochondrial release and caspase-3 cleavage activation (Li W. et al., 2009; Lee H. S. et al., 2014b). In HT-29 cells, this flavonol induces apoptosis and inhibits IGF-IR and ErbB3 signaling (Lee H. S. et al., 2014a). Kaempferol is also able to induce G1 and G2/M cell cycle arrest by inhibiting the activity of CDK2, CDK4, and Cdc2 (Cho et al., 2013).

Monotherapy with kaempferol or TRAIL alone showed a slight effect on apoptosis induction in SW480 and DLD-1 CRC cells, while the combination therapy induced a dramatic apoptosis increase in a kaempferol dose-dependent manner. This means that kaempferol is able to sensitize these CRC cells to TRAIL-induced apoptosis. Interestingly, this combination of drugs showed very low cytotoxicity in PBMC normal cells (Yoshida et al., 2008).

\section{Quercetin}

Quercetin (Figure 1I) is an ubiquitous flavonol in nature, where it is found in onion, apples, and many other vegetables and fruits. Quercetin inhibits RASA1 expression in CRC cell lines, avoiding RAS activation and therefore its proliferative effects (Ranelletti et al., 2000). Quercetin was combined with TRAIL for treatment of three CRC cell lines, Caco-2 (adenoma), SW-620, and HT-29 (adenocarcinomas); demonstrating that this flavonol is a potent sensitizer to TRAIL-induced apoptosis in a synergistic manner (SW-620 and HT-29), whereas this combination resulted in an additive effect in the case of adenoma cells (Caco-2). These pro-apoptotic effects seem to be associated with a membrane distribution of quercetin in lipid rafts domains, regions which are rich in cholesterol, sphingolipids, and TRAIL death receptors. This membrane distribution could be the initiator for signal cascades causing TRAIL-mediated apoptosis (Psahoulia et al., 2007).
Quercetin has been also used in combination with 5-FU in vitro, treating CO115 (p53 positive) and HCT15 (p53 negative) CRC cell lines. This combination of drugs showed higher apoptosis levels in CO115 cell line, in a synergistic manner, but an additive effect in HCT15 cells. This enhanced apoptosis was even higher than with 100 times higher 5-FU concentration in monotherapy. p53 may elicit this synergistic pro-apoptotic effects by enhancing caspase 3 activation and diminishing Bcl-2 (antiapoptotic) levels. This involvement of p53 is reinforced when a siRNA is used to silence p53 expression in CO115 cells, losing the synergistic effect of this combination of drugs (Table 2; Xavier et al., 2011).

\section{Epigallocatechin}

(-)-Epigallocatechin-3-gallate (EGCG, Figure 1J) is the major polyphenolic constituent of green tea, representing 200-300 mg/brewed cup (Singh et al., 2011). The antitumor effects of this and other flavanols are widely supported by epidemiological, in vitro, animal and clinical studies (Singh et al., 2011). For example, different concentrations of grape seed extracts [rich in (-)-epicatechin] were tested in combination with 5-FU $100 \mu \mathrm{M}$ in Caco-2 cells, showing a slightly synergistic effect on cell apoptosis (Cheah et al., 2014).

EGCG and related compounds are able to inhibit several critical signal transduction pathways in cancer cells. For example, EGCG inhibits multiple RTKs (Receptor Tyrosine Kinase) as the IGF/IGF1R system, EGFR, and HER2 receptors, which play key roles in CRC cell proliferation (Shimizu et al., 2005; Adachi et al., 2008, 2009). EGCG also blocks cell proliferation and cell migration in CRC cells, by inhibiting the signaling pathway TF (Tissue Factor)/VIIa/PAR2 (Protease-Activated Receptor 2) that usually mediates ERK1/2 phosphorylation and final activation of the pro-inflammatory NF-k $\beta$. This lower activity of the transcription factor NF-kB induces an up-regulation of caspase7 and a down-regulation of MMP-9 matrix metalloprotease expression, affecting proliferation and migration of tumor cells (Table 2; Zhou et al., 2012).

Furthermore, EGCG is an epigenetic regulator, which contributes to degradation of DNMT3A (DNA Methyltransferase 3A) and HDACs (Histone Deacetylases) through a process of ubiquitination in CRC cells sensitive to methylation. These effects, together with histones deacetylation, are very important epigenetic mechanisms in tumorigenesis, as they are responsible for silencing various tumor suppressor genes and other ones involved in cell cycle regulation and apoptosis (Moseley et al., 2013). Therefore, EGCG is able to restore the expression of genes involved in tumor suppression such as RXRalpha (Retinoid X Receptor alpha) that are silenced by epigenetic processes in tumor cells (Morris et al., 2016).

Also, it is remarkable the effect exerted by EGCG at the level of CSCs, downregulating Notch signaling, a membrane receptor, which is directly involved in the differentiation and proliferation of CRC stem cells (Jin et al., 2013).

Based on these anti-proliferative, anti-metastatic and epigenetic activities for EGCG, its effectiveness in combination with anticancer drugs has been tested. The combination of 5-FU with EGCG resulted in a synergistic growth inhibition in 
several human CRC cell lines (DLD-1, SW480, and COLO201) (Kumazaki et al., 2013). The same combination on HT-29 and HTC-116 CRC cells reduced cell viability significantly compared with the monotherapies. The EGCG potentiating effect on the 5-FU is supposed to be due to a downregulation in the expression of $\mathrm{ABC}$ transporters, which causes higher intracellular 5-FU concentrations (Hwang et al., 2007b; Wubetu et al., 2015).

Sodium butyrate is a non-toxic compound naturally produced in the colon after microbial fermentation of dietary fiber, which shows strong antitumor effects only on transformed colonocytes. Combination of EGCG and sodium butyrate on HT-29 tumor cells caused a synergistic reduction in survivin protein and mRNA levels, an anti-apoptotic protein highly expressed in CRC (Saldanha et al., 2014).

Another compound inducing apoptosis in tumor colonocytes, sulindac, is a NSAID inhibiting COX-1 (expressed constitutively in all tissues) and COX-2 (highly expressed in CRC and induced by cytokines). Although, sulindac has side effects due to this broad cyclooxygenases inhibition, its combination with EGCG reduces them due to an enhanced inhibition of COX2 (Suganuma et al., 1999). This synergistic effect has been also observed in rats developing CRC by induction with the chemical inducer azoxymethane (Ohishi et al., 2002).

\section{Genistein}

Genistein (Figure 1K) is an isoflavone which can be found in high concentrations in soybeans, lentils, beans, and chickpeas. Numerous epidemiological studies have reported a negative correlation between the incidence of CRC and diets rich in soybean (Spector et al., 2003; Rossi et al., 2006). This isoflavone has a growing interest as a pro-apoptotic agent because of its specific and almost exclusively activity against tumor cells (as CRC) rather than normal ones (Marín et al., 2015). Genistein acts by increasing the expression of proapoptotic proteins as Bax or p21 (Yu et al., 2004), by inhibiting NF-k $\beta$ (Luo et al., 2014) and topoisomerase II (Mizushina et al., 2013), by regulating ERB expression (Pampaloni et al., 2014), by suppressing the carcinogen induction of $\mathrm{WNT} / \beta$ catenin signaling pathway (Zhang et al., 2013), by increasing the expression of antioxidant enzymes such as glutathione peroxidase (Ganai and Farooqi, 2015), and by preventing human CRC metastases due to MMP2 metalloproteases inhibition (Xiao et al., 2015). All these activities can be exploited by combinatory approaches in order to prevent or to treat CRC.

As it has been mentioned above, 5-FU is widely used in the treatment of solid tumors such as CRC, but its main clinical limitation is the development of resistant phenotypes by the over-expression of anti-apoptotic proteins or cell proliferation factors. In order to overcome this resistance problems, a combinated treatment with genistein on HT-29 cells resistant to 5-FU showed a significant reduction in cell viability compared to the monotherapy. These experiments demonstrated a synergistic effect on cell growth inhibition by over-expression of pro-apoptotic $p 53$ and $p 21$ genes and downregulation of survival genes such as Glut-1. However, the main mechanism involved in this combination was due to COX-2 expression inhibition (Hwang et al., 2005). In a similar way, combination of genistein with cisplatin also inhibited cell growth and induced apoptosis in a synergistic manner in HT-29 CRC cells, by inhibiting tyrosine kinases (Hu et al., 2014). Finally, combination with dexamethasone also shows synergistic effects by increasing p21 levels in Colo320 HSR cells, inhibiting their growth (Park et al., 2001).

Together with chemotherapy, radiotherapy also plays a crucial role in the treatment of rectal cancer, however, in more than $70 \%$ of patients, it causes side effects on the gastrointestinal system, as mucositis due to the generation of free radicals by ionizing radiation, which causes oxidative damage to normal colonocytes. A solution to this problem would be to combine radiotherapy with natural radioprotective agents (Jagetia, 2007). In this sense, the remarkable antioxidant activity of genistein, combined with its ability to activate antioxidant pathways, makes it a perfect candidate to protect against radiation cellular damage. Following this hypothesis, CT26 CRC cells were injected into BALB/c mice, and animals were treated with radiotherapy in the abdominal area. After a combination with genistein, this isoflavone reduced the apoptosis in normal cells and improved morphological changes in healthy intestinal mucosa. Also, tumors size was lower in mice subjected to combination therapy (Table 2; Son et al., 2013).

The epidermal growth factor receptor (EGFR) plays a very important role in tumor progression because binding of its ligands initiates a cascade of intracellular phosphorylations that ultimately triggers genes associated with cell proliferation, survival, or invasion. This receptor is over-expressed in tumor cells and diverse drugs inhibit this tyrosine kinase, although resistance phenotypes usually appear after irradiation (Singh et al., 2016). Interestingly, pretreatment with genistein during 24 $\mathrm{h}$ before irradiation was able to perform a synergistic effect on irradiated HTC116 cells survival $(\mathrm{CI}<0.7)$, due to an enhanced EGFR inhibition (Gruca et al., 2014).

\section{Silymarin}

Silymarin is a flavolignan extract from milk thistle (Sylibum marianum). This flavolignans mixture contains silibinin (silybin $\mathrm{A}$ and $\mathrm{B}$, the most active compounds, Figure $1 \mathrm{~L})$, isosilybin (A, B), silydianin, and silychrystin (Lee et al., 2006). Silybins induce cell cycle arrest and apoptosis by acting on cyclin dependent kinases (CDKs).

Silymarin has been tested in combination with doxorubicin and paclitaxel against CRC cells, in a cell line sensitive to doxorubicin (LoVo) and its multidrug resistant isogenic version (LoVo/DX). Twenty-four hour prior to treatment with both drugs, silymarin was used in these cells, showing a synergistic effect in LoVo cell line, but not in LoVo/DX cells, where an additive effect was observed. This additive effect may be valuable when dealing with in vivo experiments, as any contribution to reduce doxorubicin doses would also reduce its side effects, mainly associated to cardiotoxicity (Figure 3). This cardiotoxicity is due to formation of iron-related free radicals, as well as damages to mitochondrial $\mathrm{NAD}(\mathrm{P}) \mathrm{H}$ oxidase complex 
(Thorn et al., 2011). Silymarin causes higher intracellular drug concentrations in LoVo cells due to a repression of P-gp pump (Pglycoprotein, MDR1). However, in LoVo/DX cells, the strong Pgp overexpression prevents this sensitizing effect (Colombo et al., 2011).

Silibinin also enhances metformin antiproliferative effects. Combination of this antidiabetic agent at $10 \mathrm{mmol} / \mathrm{L}$ plus $100 \mu \mathrm{mol} / \mathrm{L}$ of silibinin in COLO205 CRC cell line showed a synergistic inhibition of $60 \%$ in cell survival, which did not affect normal HCoEpiC cells. Monotherapy at these concentrations had no effects. This combination of drugs increased caspase 3 activation and AIF expression, resulting in apoptosis activation by extrinsic and mitochondrial ways. A role for the PTEN/Akt pathway in this apoptosis induction in cancer cells was also observed, with increased PTEN levels and decreased phosphorylated protein kinase B (p-Akt) (Table 2; Tsai et al., 2015).

Vanadium (IV) complexes have been tested in combination with silibinin and chrysin against HT-29 cell line, showing increased cytotoxic effects at $100 \mu \mathrm{M}$ vanadyl ion in comparison with monotherapies $(280 \mu \mathrm{M}$ vanadyl). In this combination, chrysin induces cell cycle arrest in $\mathrm{G}_{2} / \mathrm{M}$ transition, while silibinin induces apoptosis due to caspases activation and NF- $\mathrm{KB}$ inhibition (León et al., 2015).

\section{Flavopiridol}

Flavopiridol (Alvocidib, Figure 1M) is a semi-synthetic flavonoid-like derivative, generated from rohitukine, an alkaloid from the bark of Dysoxylum binectariferum, a tree from India (Kelland, 2000). Flavopiridol inhibits cyclin-dependent kinases (CDKs), targeting the ATP-binding pocket of their catalytic subunit, as Cdk1, Cdk2, Cdk4, Cdk6, Cdk7, and Cdk9. Also, it inhibits other kinases like PKA, PKC, Erk-1, EGFR, and other receptor associated protein kinases. Flavopiridol blocks cell cycle in $G_{1} / S$ and $G_{2} / M$ transitions by lowering expression levels of cyclin D1, p27 $7^{\text {Kip1 }}$, and p21 $1^{\text {Waf1/Cip1 }}$. Low cyclin D1 levels cause a reduction in Cdk4 concentration, leading to an accumulation of hypophosphorylated retinoblastoma protein $(\mathrm{Rb})$, which causes cell cycle arrest. Low $\mathrm{p} 27^{\mathrm{Kip} 1}$ or $\mathrm{p} 21^{\text {Waf1/Cip1 }}$ levels also cause a reduction in Cdk2 concentration, inducing cell cycle arrest in $\mathrm{G}_{1}$ phase and inhibiting EEF1B2 elongation factor, which blocks RNApol II transcription of Newcomb (2004).

Flavopiridol is a potent apoptosis inducer in tumor cells, via the mitochondrial pathway (release of cytochrome $\mathrm{c}$ or caspases activation), but also via AIF (apoptosis-inducing factor) pathway (Achenbach et al., 2000). This pro-apoptotic effect is enhanced as flavopiridol also inhibits Akt activation, leading to NF- $\kappa$ B inactivation and therefore to an inhibition of proliferation processes (Takada and Aggarwal, 2004). Therefore, this flavonoid derivative triggers apoptosis and at the same time inhibits proliferation.

Irinotecan, a semisynthetic analog of the natural alkaloid camptothecin, and SN-38, the irinotecan bioactive metabolite, prevents DNA from unwinding by inhibiting topoisomerase 1 . Combination of $\mathrm{SN}-38$ treatment followed by flavopiridol in HCT116 cell line and its null isogenic p53 (-/-) equivalent showed apoptosis induction only in the p53 wild type cell line. Here, p53 produced Rad51 mRNA downregulation, a gene coding for a DNA-repair protein (Ambrosini et al., 2008).

In a mouse xenograft model with HCT116 cell line, irinotecan treatment followed by flavopiridol showed a significant decrease in tumor growth compared to monotherapies. This study suggests changes in the choline kinase activity and decreased phosphocholine (Motwani et al., 2001; Darpolor et al., 2011). Since diarrhea is one of the most common side effect associated to irinotecan treatment, this synergistic effect among flavopiridol and irinotecan may be a valuable combination for preventing or reducing this gastrointestinal toxicity associated to this camptothecin derivative (Fuchs et al., 2003) (Figure 3).

Sequential treatment with docetaxel, flavopiridol, and 5-FU in HCT116 cell line showed an 8-fold increase in caspase activity, with much lower increase if the three compounds were added simultaneously, in pairs or separately. Using this triple combination in mice xenografts with HCT116 caused a decrease in tumor volume by $95 \%$ (50\% reduction for single drug treatment, $70 \%$ reduction for two drugs combination; Table 2; Guo et al., 2006).

A phase I trial of weekly, sequential docetaxel followed by flavopiridol (after $4 \mathrm{~h}$ first treatment) in patients with advanced solid tumors showed that this combination of drugs was well tolerated, with one dose-limiting toxicity occurring at $70 \mathrm{mg} / \mathrm{m}^{2}$ flavopiridol. Docetaxel common toxicity effects are mostly associated to neutropenia (Ho and Mackey, 2014). Also, one complete response was observed in a patient with pancreatic carcinoma, as well as four partial responses in pancreatic (1), breast (2), and ovarian (1) tumors. Stable disease was observed in ten patients (27 patients in total; Fornier et al., 2007).

\section{TERPENES}

Another large and diverse class of organic compounds where some of them have shown a promising role against CRC in combination with other drugs are the terpenes. Terpenes are the structurally most diverse class of all plant and fungal bioactive metabolites, with more than 50,000 molecules. All terpenes derive from the condensation of dimethylallyl diphosphate (DMAPP) and isopentenyl diphosphate (IPP) precursors, which may be linked together "head to tail" to form linear chains or may be arranged to form rings (Klein-Marcuschamer et al., 2007). Terpenes are classified, according to the number of biosynthetic isoprene units, in monoterpenes (10 carbon atoms, C10), sesquiterpenes (C15), diterpenes (C20), triterpenes (C30), and tetraterpenes (C40) (Misawa, 2011). In addition, terpenes that have undergone oxidation steps are called terpenoids. Some examples are essential oils such as limonene (C10, flavoring agent), vitA (C20), $\beta$-carotene (C40), and steroids (C30, cholesterol, testosterone).

\section{Artesunate}

Artesunate (Figure 2C) is the hemisuccinate ester of artemisin, a sesquiterpene found in Artemisa annua (a traditional Chinese herb), widely used for malaria treatment as ROS inducer in the Plasmodium parasite (Meshnick, 2002). Artesunate is 


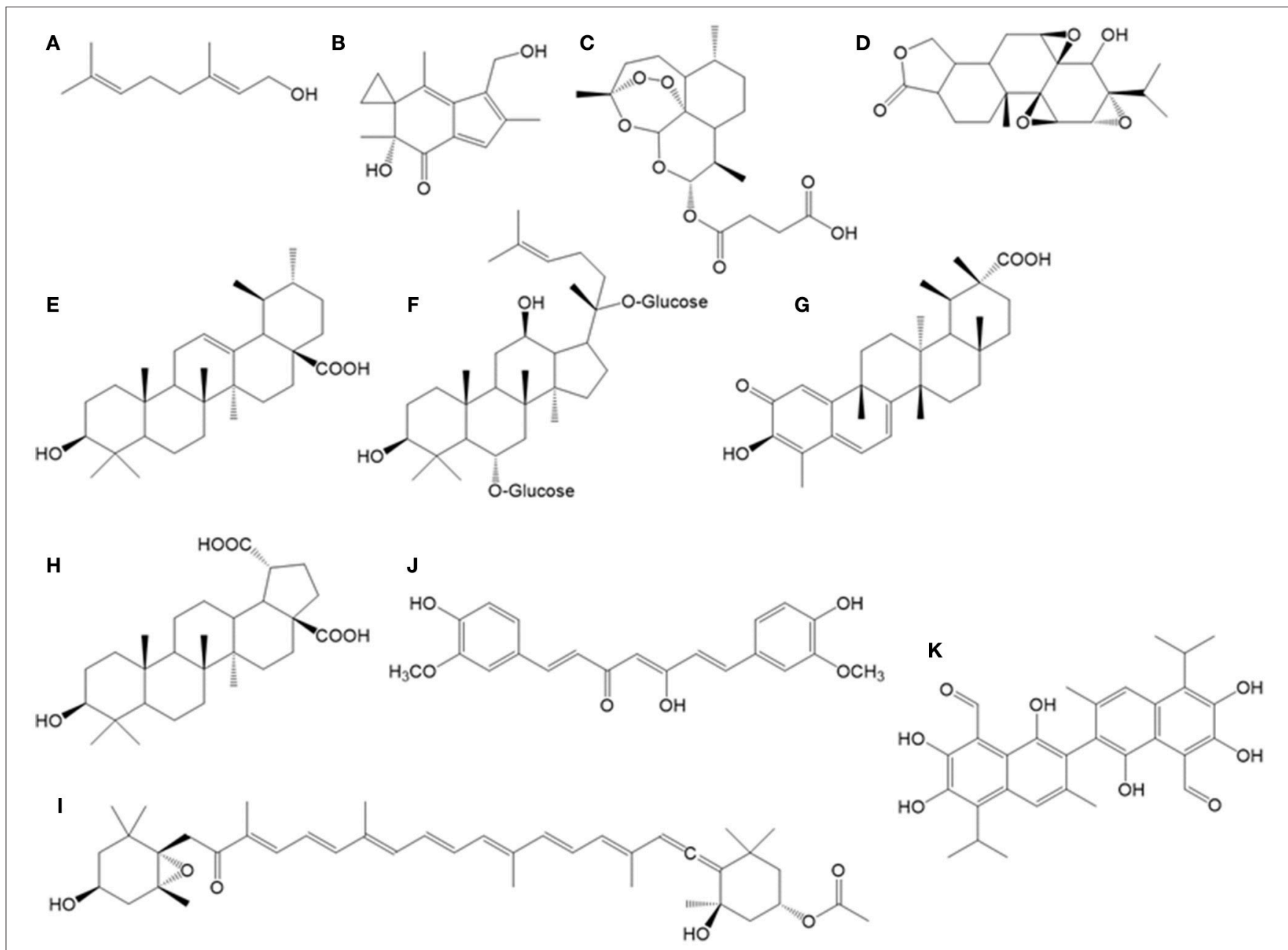

FIGURE 2 | Chemical structures of bioactive terpenoids and other compounds described in the text. (A) geraniol, (B) irofulven, (C) artesunate, (D) triptolide, (E) ursolic acid, (F) ginsenoside, (G) celastrol, (H) betulinic acid, (I) fucoxanthin, (J) curcumin, (K) gossypol.

cytotoxic in HCT116 cells, inducing a cell cycle arrest at $\mathrm{G}_{1}$, due to cyclin $\mathrm{D} 1$ downregulation and $\mathrm{p} 21$ overexpression. The treatment of these CRC cells with artesunate $(1.9 \mu \mathrm{M})$ or oxaliplatin (another agent also causing ROS stress in cells, together with other alkylating activities on DNA; $4 \mu \mathrm{M}$ ) causes $50 \%$ cell killing. However, the same effect can be obtained with a combination of just $0.65 \mu \mathrm{M}$ artesunate plus $1.6 \mu \mathrm{M}$ oxaliplatin, which reinforces the used of artesunate as a possible adjuvant chemotherapy molecule (Liu et al., 2011).

\section{Geraniol}

The monoterpene geraniol (Figure 2A) is a main component in commercially important essential oils (rose, lemon, etc.), with wide use in perfumes. In vitro combination of geraniol $(150 \mu \mathrm{M}$, $\left.\mathrm{IC}_{30}\right)$ plus $5-\mathrm{FU}\left(0.25 \mu \mathrm{M}, \mathrm{IC}_{30}\right)$ on Caco-2 cells increased the cell death in comparison with monotherapy, causing over $20 \%$ reductions cell survival. In a tumor xenograft model for TC118 CRC cell line, combination of geraniol $(150 \mathrm{mg} / \mathrm{kg})$ plus $5-\mathrm{FU}$
(40 mg/kg) showed a clear $83 \%$ reduction in tumors size, whereas monotherapies with these concentrations caused only 26 and $30 \%$ tumor reductions, respectively (Carnesecchi et al., 2004).

In a CRC animal model using the mutagen dimethylhydrazine, oral geraniol $(25 \mathrm{mg} / 100 \mathrm{~g})$ was administered in order to test its effects in CRC prevention at early stages (aberrant crypt foci reduction in colon mucosa, ACF). After 9 weeks, a significant $37 \%$ reduction in colon ACF was observed with respect to control animals, together with enhanced apoptosis parameters. This protection was also accompanied by a $30 \%$ reduction in the cellular levels of $\mathrm{Bcl}-2$ in geraniol treated animals, an anti-apoptotic protein, whose low levels may explain the geraniol antitumor effect in colon mucosa (Table 3). These results may open the path to the study of other non-cyclic monoterpenes as antitumor agents (Vieira et al., 2011).

\section{Irofulven}

Irofulven (Figure 2B) is a semi-synthetic derivative of illudin S, a sesquiterpene isolated from the mushroom Omphalotus illudens. 
TABLE 3 | Summary of main in vitro and in vivo synergistic effects of terpenoids and other compounds in combination with chemotherapeutic compounds against CRC.

\begin{tabular}{|c|c|c|c|c|c|}
\hline References & $\begin{array}{l}\text { Tested } \\
\text { molecule }\end{array}$ & $\begin{array}{l}\text { In combination } \\
\text { with }\end{array}$ & Experimental model & Main result & Proposed mechanism \\
\hline $\begin{array}{l}\text { Carnesecchi et al., } \\
\text { 2004; Vieira et al., } 2011\end{array}$ & Geraniol & $5-\mathrm{FU}$ & Caco-2 cell line & $\begin{array}{l}\text { Synergistic: } 20 \% \text { reduction in cell } \\
\text { survival }\end{array}$ & Down-regulation of $\mathrm{Bcl}-2$ \\
\hline $\begin{array}{l}\text { Carnesecchi et al., } \\
2004\end{array}$ & Geraniol & 5-FU & Mice xenograft (TC118) & $\begin{array}{l}\text { Synergistic: } 80 \% \text { reduction in } \\
\text { tumor size }\end{array}$ & Unknown \\
\hline Serova et al., 2006 & Irofulven & Oxaliplatin & HT-29 cell line & Synergistic: reduced cell survival & Unknown \\
\hline Britten et al., 1999 & Irofulven & Irinotecan & Mice xenograft (HT-29) & Synergistic: tumor size reduction & Unknown \\
\hline Liu et al., 2011 & Artesunate & Oxaliplatin & HCT116 cell line & Synergistic: 50\% cell killing & ROS induction \\
\hline Liu et al., 2014 & Triptolide & Oxaliplatin & SW480 cell line & Synergistic: $62 \%$ cell killing & $\begin{array}{l}\text { Apoptosis induction, blocking of } \\
\beta \text {-catenin translocation to } \\
\text { nucleus }\end{array}$ \\
\hline Liu et al., 2014 & Triptolide & Oxaliplatin & Mice xenograft (SW480) & $\begin{array}{l}\text { Synergistic: } 60 \% \text { tumor growth } \\
\text { reduction }\end{array}$ & Unknown \\
\hline $\begin{array}{l}\text { Koh et al., 2012; } \\
\text { Prasad et al., } 2012\end{array}$ & Ursolic acid & Radiotherapy & $\begin{array}{l}\text { CT26 and HCT116 cell } \\
\text { lines }\end{array}$ & Synergistic: $55 \%$ cell killing & $\begin{array}{l}\text { Apoptosis induction, caspase } 3 \\
\text { activation, ROS increase, GSH, } \\
\text { NF-kB and Bcl-2 reductions }\end{array}$ \\
\hline Wang et al., 2015 & Ginsenolides & $5-F U$ & Mice xenograft (HCT116) & Synergistic: reduced tumor size & $\mathrm{G}_{1}$ arrest \\
\hline Kim et al., 2009 & Ginsenolides & Docetaxel & HCT116 cell line & Synergistic: increased cell death & NF-kB inhibiton, $\mathrm{Bcl}-2$ repression \\
\hline Zhu et al., 2010 & Calastrol & TRAIL & SW620 cell line & Synergistic: increased cell killing & Apoptosis induction \\
\hline Jung et al., 2007 & Betulinic acid & $\begin{array}{l}\text { 5-FU, oxaliplatin, } \\
\text { irinotecan }\end{array}$ & SNU-C5 cell line & $\begin{array}{l}\text { Synergistic: increased cell killing, } \\
\text { reduction in chemoresistance }\end{array}$ & Apoptosis induction (caspase 3) \\
\hline Li et al., 2007 & Curcumin & Oxaliplatin & Lo-Vo cell line & Synergistic: growth inhibition & Unknown \\
\hline Anitha et al., 2014 & Curcumin & $5-\mathrm{FU}$ & HT-29 & Synergistic: increased cells killing & Apoptosis induction \\
\hline Murakami et al., 2013 & Curcumin & Turmerones & $\begin{array}{l}\text { CRC mouse model } \\
\text { (dimethyl-hydrazine) }\end{array}$ & Synergistic: tumor size reduction & Apoptosis induction \\
\hline Yue et al., 2016b & Curcumin & Bevacizumab & Mice xenograft (HT-29) & Synergistic: tumor size reduction & Apoptosis induction \\
\hline $\begin{array}{l}\text { Zhang et al., 2003; Lan } \\
\text { et al., } 2015\end{array}$ & Gossypol & $5-\mathrm{FU}$ & Mice xenograft (HT-29) & Synergistic: tumor size reduction & $\begin{array}{l}\text { Apoptosis induction, chemical } \\
\text { sensitization }\end{array}$ \\
\hline
\end{tabular}

It shows potent growth inhibition on a wide variety of human solid tumor cell lines and primary tumor cell types. In vivo testing has demonstrated excellent dose-related antitumor activity in several human tumor mice xenograft models.

Combination of irofulven with radiation or chemotherapeutic agents such as paclitaxel, irinotecan, 5-FU, mitomycin C, thiotepa, topotecan, and cisplatin have produced additive and/or synergistic inhibition of cellular proliferation in a variety of tumor types. With respect to CRC, simultaneous exposure to irofulven and cisplatin is at least additive for HCT116 cells, whereas simultaneous exposure to irofulven and 5-FU is additive for HT-29 cells and synergistic for the irofulven-resistant HCT116 cell line (Poindessous et al., 2003). Combination of irofulven with oxaliplatin also led to synergistic activity in HT29 cell line (Serova et al., 2006). In a mice xenograft model for HT-29 cells, combination of irofulven and irinotecan, significant reduction in tumor weights occurred with partial responses in nearly all of the animals and some animals achieving complete responses (Table 3; Britten et al., 1999).

\section{Triptolide}

Triptolide (Figure 2D) is a diterpene from Tripterygium wilfordii tree, used as anti-inflammatory and antitumor in traditional Chinese medicine. Individual treatments with triptolide or oxaliplatin during $48 \mathrm{~h}$ in SW480 cell line showed $\mathrm{IC}_{50}$ values of $16.7 \mathrm{ng} / \mathrm{mL}$ and $20.8 \mu \mathrm{g} / \mathrm{mL}$, respectively. However, in combination with $10 \mu \mathrm{g} / \mathrm{mL}$ oxaliplatin, $8 \mathrm{ng} / \mathrm{mL}$ of this diterpene was able to induce $62 \%$ apoptosis. This synergistic effect was due to an inhibition of nuclear translocation of the transcription factor $\beta$-catenin under combinatory conditions, causing that this cell progression factor remains accumulated in the cytoplasm. Also, in a mice xenograft model for this cell line, combination of triptolide $(0.1 \mathrm{mg} / \mathrm{kg})$ with oxaliplatin $(5 \mathrm{mg} / \mathrm{kg})$ also showed this synergistic effect, reducing tumors growth by $60 \%$ (Table 3). This positive effect was not accompanied by a significant increase in ALT and AST transaminases (biomarkers for hepatic damage) nor in blood urea nitrogen (biomarker for renal damage; Liu et al., 2014). In a similar way, combination of triptolide $(0.15 \mathrm{mg} / \mathrm{kg})$ plus 5 -FU $(12 \mathrm{mg} / \mathrm{kg})$ in another xenograft model with HT-29 cell line caused a reduction of 96\% tumor growth for 3 weeks treatment, with no side effects observed (Tang et al., 2007). These results open the way for the use of triptolide in the treatment of solid tumors in preclinical trials (Jiang et al., 2001; Fidler et al., 2003).

\section{Ursolic Acid}

The triterpene ursolic acid (Figure 2E) is found in diverse herb species as basil and rosemary. This antioxidant compound is able 


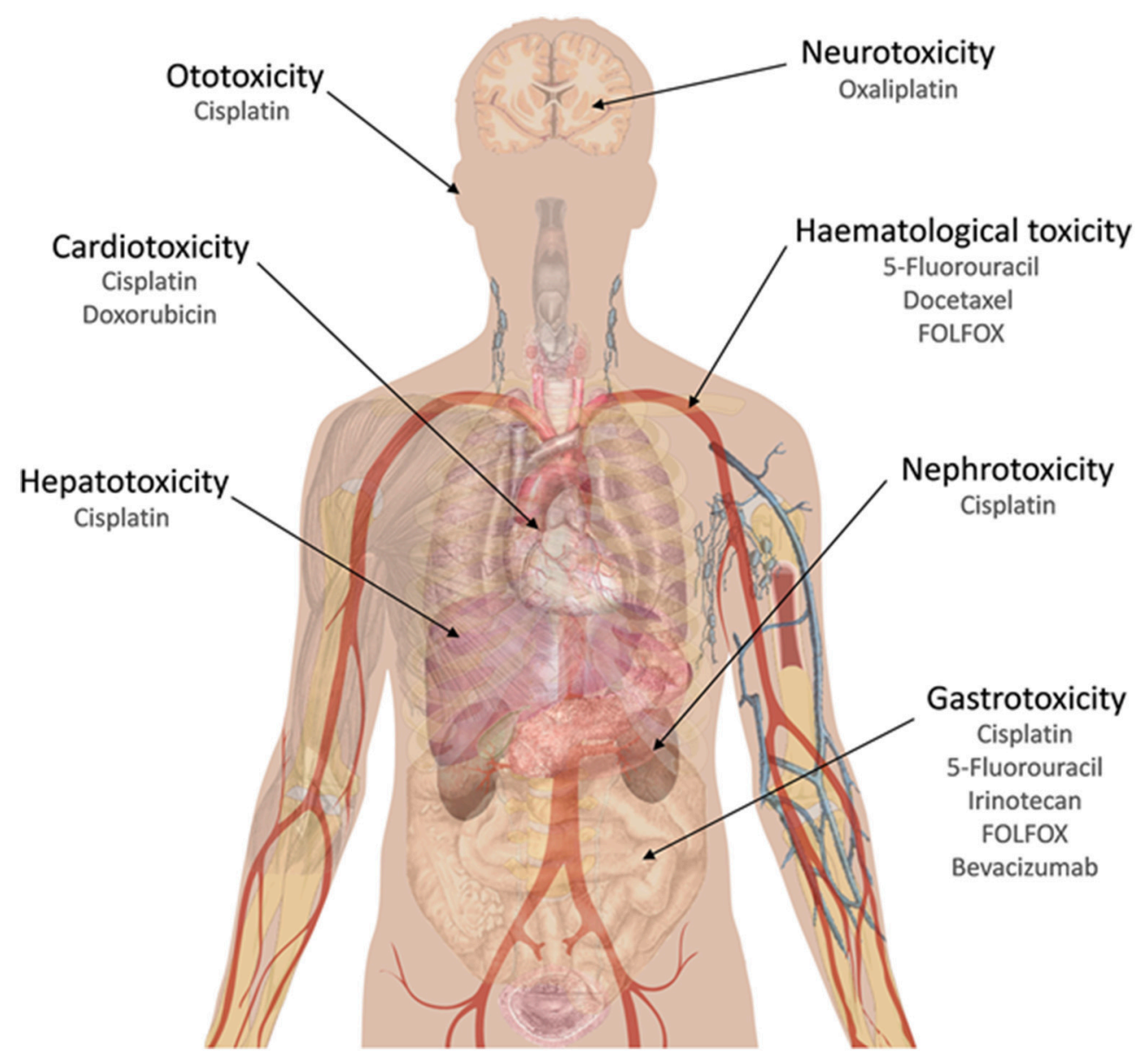

FIGURE 3 | Chemotherapy compounds that have been mentioned in this work and their main side effects.

to modulate cellular redox status in normal cells, but in tumor cells it exerts pro-oxidative action. This is an important fact when dealing with tumor cells and radiotherapy, as ionizing radiation works by increasing cell oxidative damage in transformed cells, leading to apoptosis. In this sense, radio-resistance status can be avoided or reverted by using drugs able to increase ROS and its mitochondrial, DNA and membranes damages.

Using in vitro experiments with CT26 mouse CRC cells, a synergistic effect has been described for a combination of ursolic acid plus radiotherapy, where apoptosis was enhanced $55 \%$, via caspase 3 activation. In these co-treated tumor cells, it was observed higher peroxides formation, lower GSH levels and extended mitochondrial damage (Koh et al., 2012). These pro-apoptotic effects of ursolic acid have been reproduced in other CRC cell lines as HCT116, where this compound was able to reduce the pro-inflammatory NF-kB cytokine, the pro-metastatic MMP-9 matrix metalloprotease, and the survival effectors Bcl-2 and survivin. All these changes in expression of key cancer modulators were reinforced when conducting these in vitro experiments with ursolic acid and capecitabine together (Table 3; Prasad et al., 2012).
In a mouse xenograft model with HCT116 cells, combination of ursolic acid with capecitabine caused a $68 \%$ reduction in tumor volume, also diminishing distant metastasis to lung around 60\% (Prasad et al., 2012).

\section{Ginsenosides}

Panaxadiol is a ginsenosides (Figure 2F) triterpene found both in ginseng (Panax ginseng) and in notoginseng (Panax pseudoginseng). Previous studies have shown the antitumor activities of these compound on several cell lines and their targeting on multiple cancer signaling pathways (Park et al., 1999; Jin et al., 2003; Gao et al., 2013). Notoginseng extract, which contains high amounts of ginsenosides, enhances 5FU induced apoptosis in human CRC cells (Wang et al., 2007a,b). Looking for specific bioactive components in these extracts, panaxadiol was found to be the component which caused enhanced apoptosis in HCT116 cell line (Li X. L. et al., 2009). Similar results were obtained with protopanaxadiol, another ginseng metabolite that significantly enhanced 5-FU effects on HCT116 cells by inducing arrest in $G_{1}$ phase and apoptosis. These in vitro data were confirmed by using an in vivo mice xenograft model, showing that protopanaxadiol 
and 5-FU co-administration very significantly reduced the tumor size in a dose-related manner (Table 3; Wang et al., 2015).

Another member of this family, ginsenoside $\mathrm{Rg} 3$, is able to repress NF-kB expression in HCT116 cell line, leading to apoptosis, with a $\mathrm{IC}_{50}$ value of $100 \mu \mathrm{M}$. NF-kB is usually activated in these and other tumor cells. Twenty-four hour combination of $50 \mu \mathrm{M}$ ginsenoside $\mathrm{R} 3$ plus $5 \mu \mathrm{M}$ docetaxel in this cell line resulted in a synergistic NF-kB inhibition, absent in the monotherapy experiments at these concentrations. This proapoptosis effect was due to $\mathrm{Bcl}-2$ repression and expression of the pro-apoptotic proteins caspase 3 and Bax, which demonstrated the chemosensitization of these tumor cells to docetaxel in the presence of ginsenosides R3 (Kim et al., 2009).

\section{Celastrol}

Celastrol (Figure 2G) is a triterpene from the bark of the $T$. wilfordii tree. This compound inhibits the heat shock protein HSP90, blocking its interaction with Cdc37. TRAIL addition to cultures of SW620 CRC cells shows an $\mathrm{IC}_{50}$ value of 423.5 $\mathrm{ng} / \mathrm{mL}$, whereas this parameter is reduced to only $121.1 \mathrm{ng} / \mathrm{mL}$ in the presence of $2 \mu \mathrm{M}$ celastrol during $72 \mathrm{~h}$, due to apoptosis induction via caspase 3; therefore, celastrol shows a synergistic effect in combination with TRAIL (Zhu et al., 2010).

\section{Betulinic Acid}

Betulinic acid (Figure $\mathbf{2 H}$ ) is an anti-inflammatory and antimalarial triterpene isolated from diverse plants, as Betula pubescens tree (birch) and many others. This compound exerts apoptosis through caspase 3 induction in SNU-C5 CRC cell line with $\mathrm{IC}_{50}$ value of $1 \mu \mathrm{g} / \mathrm{mL}$. Three resistance variants were originated from this cell line, showing increased resistance to $5-\mathrm{FU}$ (total resistance, instead $\mathrm{IC}_{50}$ of $6 \mu \mathrm{g} / \mathrm{mL}$ in parental cell line), irinotecan (5.55-fold $\mathrm{IC}_{50}$ instead of $\mathrm{IC}_{50}$ of $18 \mu \mathrm{g} / \mathrm{mL}$ in parental cell line), and oxaliplatin (total resistance, instead $\mathrm{IC}_{50}$ of $100 \mu \mathrm{g} / \mathrm{mL}$ in parental cell line). These three resistant variants were more sensitive to betulinic acid alone than the parental cell line, but more interestingly, combination of betulinic acid plus 5-FU reverted apoptosis induction in the 5-FU resistant cells. A similar reversion effect was observed with a combination of betulinic acid plus oxaliplatin in oxaliplatin-resistant cells. These results clearly demonstrate that in some cases it is possible to circumvent acquired chemoresistance by combination therapy of anticancer drugs with chemosensitizers as betulinic acid (Jung et al., 2007).

\section{Fucoxanthin}

Fucoxanthin (Figure 2I) is a tetraterpenoid carotenoid found in the edible macroalga Undaria pinnatifida, which has been associated to prevention of CRC (Kim et al., 1998). In vitro studies with Caco-2 cell line have shown that this carotenoid is able to induce apoptosis after $72 \mathrm{~h}$ exposure at $22.6 \mu \mathrm{M}$. This apoptosis induction was due to an $80 \%$ reduction in $\mathrm{Bcl}-2$ protein levels, a survival factor (Hosokawa et al., 2004).

\section{CURCUMIN}

Curcumin (Figure 2J) is a diarylheptanoid found in turmeric (Curcuma longa) that is frequently described as a chemopreventive agent for CRC (Chauhan, 2002; Goel et al., 2008; Prasad et al., 2014). Curcumin protects against chemically induced intestinal tumorigenesis in mice and rats (Huang et al., 1992, 1994; Rao et al., 1993; Kim et al., 1998; Kawamori et al., 1999) and prevents adenoma development in the gastrointestinal tract of $a p c( \pm)$ mice, a model of human familial adenomatous polyposis (Perkins et al., 2002).

A combination of liposomal curcumin with oxaliplatin in vitro at equimolar concentrations resulted in no significant enhanced growth inhibition compared with monotherapies results. However, 4:1 molar ration combinations in LoVo cells resulted in a synergistic effect. However, there was no synergistic effect for both drugs in vivo using Colo205 and LoVo mice xenografts (Li et al., 2007).

Dasatinib is a potent Src and Abl kinases inhibitor. Curcumin showed synergistic effect with this inhibitor in HCT116 and HT-29 cells under FOLFOX treatment (5-FU, leucovorin plus oxaliplatin) resistant phenotype. This combination of drugs is preferred to single agent regimens, as oxaliplatin alone, which has limited activity. FOLFOX inhibited cellular growth, invasion and colonosphere formation and also reduced CSCs populations as evidenced by the decreased expression of their specific markers (CD133, CD44, CD166, and ALDH; Nautiyal et al., 2011).

Different studies have also reported the potential enhancement of 5-FU antitumor efficacy in combination with curcumin/hexahydrocurcumin, both in vitro (Du et al., 2006; Srimuangwong et al., 2012a) and in vivo (Srimuangwong et al., 2012b). Curcumin can potentiate as well the pro-apoptotic and anti-metastatic effects of capecitabine, a prodrug that is enzymatically converted to 5-FU in the body (Kunnumakkara et al., 2009). In a recent phase I clinical trial using a combination of curcumin with FOLFOX, this combination of drugs enhanced anti-proliferative effects in patient-derived explants, indicating that curcumin can reduce CRC cells survival (Patel et al., 2008; James et al., 2015). Oxaliplatin treatment causes neurosensory toxicity and paresthesia, but combination therapy with FOLFOX regimen leads to common neutropenia, neurotoxicity, and diarrhea (Braun and Seymour, 2011) (Figure 3).

Curcumin is relatively safe for normal cells, but it can induce tumor apoptosis by different pathways (Hanif et al., 1997; Ravindran et al., 2009; Kantara et al., 2014), as it has demonstrated in several clinical trials (Bar-Sela et al., 2010; Gupta et al., 2013). However, its poor bioavailability is still regarded as a major problem for its therapeutic use (Anand et al., 2007). One approach to enhance curcumin absorption by colonocytes, to increase in vitro bioactivity and in vivo bioavailability is nanoencapsulation. This promising process reduces the non-selective exposure of this nutraceutical and improves the plasma half-life of the drug (Tsai et al., 2011; Yallapu et al., 2012). For example, 5-FU and curcumin were individually 
entrapped in chemically modified chitosan nanoparticles that were characterized for its in vitro hemocompatibility, drug release profile, cellular internalization, in vitro combinatorial antitumor effects in HT-29 cells and plasma concentration time profile by pharmacokinetics (in Swiss Albino mouse model). These experiments demonstrated that nanoparticles were blood-compatible, the release profile over a period of 4 days was sustained, the antitumor effects on CRC cells were enhanced and the plasma concentrations of both components in the mouse model were improved and prolonged up to $72 \mathrm{~h}$, longer than bare drugs (Anitha et al., 2014).

A synergistic combination of curcumin and resveratrol has been also described. Both agents, acting together, inhibited the constitutive activation of EGFRs and IGF-1R in HCT-116 CRC cells. A test with a mice xenograft mouse model of CRC showed that the combination of resveratrol and curcumin (at doses of 50 and $500 \mathrm{mg} / \mathrm{kg}$, respectively, administered by gavage for 3 weeks) is highly effective in inhibiting tumor growth and stimulating apoptosis of CRC cells in vivo, through attenuation of NF- $\mathrm{BB}$ activity (Table 1; Majumdar et al., 2009).

Turmerones are several structurally related non-polar sesquiterpenes found in turmeric ethanol extracts, which could increase curcumin accumulation inside colonocytes, but this curcumin-free fraction also exhibits biological activities. Pharmacokinetic results showed that plasma curcumin levels in mice fed with turmeric extract were the highest ones (Aggarwal et al., 2013; Yue et al., 2016b). Interestingly, the combination of curcumin and turmerones abolishes tumor formation when fed to a dimethyl-hydrazine-initiated and DSS-promoted mouse model of CRC (Murakami et al., 2013). Also, in a HT-29 tumor xenograft mice model, feeding with turmeric ethanol extract caused a greater tumor size reduction than feeding with curcumin (Yue et al., 2016a,b). The presence of turmerones increases curcumin accumulation inside colonocytes and could enhance curcumin antitumor activity in mice models. Bevacizumab is a monoclonal antibody targeting vascular endothelial growth factor. It has been used in combination with turmeric ethanol extract (including curcumin) for treatment of mice harboring HT-29 xenografts. Also, a combination therapy of turmeric extract plus bevacizumab treatment significantly inhibited tumor growth. These inhibitory effects were comparable with those of FOLFOX plus bevacizumab, with no observable side-effect induced by turmeric extract treatment while significant side effects were found in FOLFOX-treated mice (Table 3; Yue et al., 2016b). Potential synergistic effects of turmerones, curcumin, and bevacizumab could eventually allow a future reduction in this antibody dosage to patients, if applied in clinic. This would lead to reduction/prevention of some rare side effects associated to bevacizumab therapy, as thrombosis, arterial hypertension, proteinuria, perforation of the gastrointestinal tract, or nasal septum, wound healing abnormalities (which may lead to postoperative bleeding in CRC surgery), irreversible leuco-encephalopathy syndrome, allergic skin rash, and hypersensitivity reactions (including flashing, pruritus, arterial hypertension, rigors, bronchoconstriction, chest pain, and sweats). These side effects also include rare spontaneous delayed (sometimes even several months after surgery) leakage from colon or rectal anastomosis after treatment with bevacizumab (Pavlidis and Pavlidis, 2013).

\section{GOSSYPOL}

Gossypol (Figure 2K) is a natural phenolic aldehyde derived from the cotton plant (Gossypium). Its antitumor properties have been studied in a variety of tumors since the 1980s, being currently evaluated in phase I and II clinical trials for its use as a single agent or in combination with other antitumor agents in a variety of hematologic, lymphoid, and solid tumors. Gossypol inhibits cell proliferation and induces apoptosis and autophagy in a variety of CRC cell lines. Also, it inhibits CRC growth in a mouse xenograft model after oral administration (Zhang et al., 2003; Lan et al., 2015). Gossypol sensitizes the antitumor activity of 5-FU, causing a synergistic cytotoxic effect in HT-29, HCT116, and RKO cells, compared with monotherapies (Table 3; Yang D. et al., 2015).

\section{CONCLUSIONS}

As a general rule, designing of combinations involving a traditional chemotherapy drug (or radiotherapy protocol) plus one or more natural bioactive compounds (including in some cases well-known nutraceuticals), could be a promising approach in order to potentially achieve improvements in the partial or complete remission of CRC tumors; and at the same time this could minimize side effects which could be associated with this drug treatment or radiotherapy (neutropenia, diarrhea, cardiotoxicity, nephrotoxicity, hepatotoxicity, etc.) (Figure 3). Most synergistic effects of these combinations have been reported in in vitro and using animal tumor models and are due to antioxidant bioactivity, apoptosis induction (via the mitochondrial or extrinsic pathways) and/or cell cycle arrest (at any checkpoint).

These beneficial effects due to the addition of a natural bioactive to the canonical drug treatment, are enhanced by the fact that these natural compounds and nutraceuticals can reinforce the drug effective concentration, which is needed in order to achieve the same therapeutic result. Also, interestingly, in some cases, addition of the bioactive compound may allow to overcome the intrinsic or acquired chemo- or radioresistance occurring in some tumor cells, as these plant or fungal compounds may modulate simultaneously diverse target pathways in the neoplastic cell, overcoming those altered cell regulatory routes which may be responsible for a particular resistance mechanism.

Finally, in many cases, these bioactives are small molecular weight compounds present in medicinal plants and foods, which would allow their potential easy oral administration, independently of painful or stressful administration methods (peritoneal, catheters, etc.). In the specific case of CRC therapy, this is a fact of enormous importance, as these molecules can easily reach the transformed colon mucosa cells. 


\section{AUTHOR CONTRIBUTIONS}

Introduction and resveratrol section were written by SR, flavonoids section was written by JF and IG, terpenoids section was written by CV and FL. Final revision was made by FL.

\section{REFERENCES}

Achenbach, T. V., Muller, R., and Slater, E. P. (2000). Bcl-2 independence of flavopiridol-induced apoptosis. Mitochondrial depolarization in the absence of cytochrome c release. J. Biol. Chem. 275, 32089-32097. doi: 10.1074/jbc.M005267200

Adachi, S., Nagao, T., To, S., Joe, A. K., Shimizu, M., Matsushima-Nishiwaki, R., et al. (2008). (-)-Epigallocatechin gallate causes internalization of the epidermal growth factor receptor in human colon cancer cells. Carcinogenesis 29, 1986-1993. doi: 10.1093/carcin/bgn128

Adachi, S., Shimizu, M., Shirakami, Y., Yamauchi, J., Natsume, H., MatsushimaNishiwaki, R., et al. (2009). (-)-Epigallocatechin gallate downregulates EGF receptor via phosphorylation at Ser1046/1047 by p38 MAPK in colon cancer cells. Carcinogenesis 30, 1544-1552. doi: 10.1093/carcin/bgp166

Aggarwal, B. B., Yuan, W., Li, S., and Gupta, S. C. (2013). Curcumin-free turmeric exhibits anti-inflammatory and anticancer activities: identification of novel components of turmeric. Mol. Nutr. Food Res. 57, 1529-1542. doi: 10.1002/mnfr.201200838

Ali, I., and Braun, D. P. (2014). Resveratrol enhances mitomycin C-mediated suppression of human colorectal cancer cell proliferation by up-regulation of p21WAF1/CIP1. Anticancer Res. 34, 5439-5446.

Almasan, A., and Ashkenazi, A. (2003). Apo2L/TRAIL: apoptosis signaling, biology, and potential for cancer therapy. Cytokine Growth Factor Rev. 14, 337-348. doi: 10.1016/S1359-6101(03)00029-7

Ambrosini, G., Seelman, S. L., Qin, L.-X., and Schwartz, G. K. (2008). The cyclindependent kinase inhibitor flavopiridol potentiates the effects of topoisomerase I poisons by suppressing Rad51 expression in a p53-dependent manner. Cancer Res. 68, 2312-2320. doi: 10.1158/0008-5472.CAN-07-2395

Amiri, F., Zarnani, A.-H., Zand, H., Koohdani, F., Jeddi-Tehrani, M., and Vafa, M. (2013). Synergistic anti-proliferative effect of resveratrol and etoposide on human hepatocellular and colon cancer cell lines. Eur. J. Pharmacol. 718, 34-40. doi: 10.1016/j.ejphar.2013.09.020

Anand, P., Kunnumakkara, A. B., Newman, R. A., and Aggarwal, B. B. (2007). Bioavailability of curcumin : problems and promises. Mol. Pharm. 4, 807-818. doi: $10.1021 / \mathrm{mp} 700113 \mathrm{r}$

Anitha, A., Sreeranganathan, M., Chennazhi, K. P., Lakshmanan, V. K., and Jayakumar, R. (2014). In vitro combinatorial anticancer effects of 5-fluorouracil and curcumin loaded $\mathrm{N}, \mathrm{O}$-carboxymethyl chitosan nanoparticles toward colon cancer and in vivo pharmacokinetic studies. Eur. J. Pharm. Biopharm. 88, 238-251. doi: 10.1016/j.ejpb.2014.04.017

Bar-Sela, G., Epelbaum, R., and Schaffer, M. (2010). Curcumin as an anti-cancer agent: review of the gap between basic and clinical applications. Curr. Med. Chem. 17, 190-197. doi: 10.2174/092986710790149738

Bode, L. M., Bunzel, D., Huch, M., Cho, G., Ruhland, D., Bunzel, M., et al. (2013). In vivo and in vitro metabolism of trans-resveratrol by human gut microbiota. Am. J. Clin. Nutr. 97, 295-309. doi: 10.3945/ajcn.112.049379

Braun, M. S., and Seymour, M. T. (2011). Balancing the efficacy and toxicity of chemotherapy in colorectal cancer. Ther. Adv. Med. Oncol. 3, 43-52. doi: $10.1177 / 1758834010388342$

Bray, F., Ren, J.-S., Masuyer, E., and Ferlay, J. (2013). Global estimates of cancer prevalence for 27 sites in the adult population in 2008. Int. J. Cancer 132, 1133-1145. doi: 10.1002/ijc.27711

Britten, C. D., Hilsenbeck, S. G., Eckhardt, S. G., Marty, J., Mangold, G., MacDonald, J. R., et al. (1999). Enhanced antitumor activity of 6hydroxymethylacylfulvene in combination with irinotecan and 5-fluorouracil in the HT29 human colon tumor xenograft model. Cancer Res. 59, 1049-1053.

Brown, V. A., Patel, K. R., Viskaduraki, M., Crowell, J. A., Perloff, M., Booth, T. D., et al. (2010). Repeat dose study of the cancer chemopreventive

\section{FUNDING}

Authors wish to thank to MINECO (Spanish Ministry or Economy and Competitiveness) for grant AGL-201020622.

agent resveratrol in healthy volunteers: safety, pharmacokinetics, and effect on the insulin-like growth factor axis. Cancer Res. 70, 9003-9011. doi: 10.1158/0008-5472.CAN-10-2364

Buhrmann, C., Shayan, P., Kraehe, P., Popper, B., Goel, A., and Shakibaei, M. (2015). Resveratrol induces chemosensitization to 5-fluorouracil through up-regulation of intercellular junctions, Epithelial-to-mesenchymal transition and apoptosis in colorectal cancer. Biochem. Pharmacol. 98, 51-68. doi: 10.1016/j.bcp.2015.08.105

Burns, J., Yokota, T., Ashihara, H., Lean, M. E. J., and Crozier, A. (2002). Plant foods and herbal sources of resveratrol. J. Agric. Food Chem. 50, 3337-3340. doi: 10.1021/jf0112973

Carnesecchi, S., Bras-Gonçalves, R., Bradaia, A., Zeisel, M., Gossé, F., Poupon, M. F., et al. (2004). Geraniol, a component of plant essential oils, modulates DNA synthesis and potentiates 5-fluorouracil efficacy on human colon tumor xenografts. Cancer Lett. 215, 53-59. doi: 10.1016/j.canlet.2004.06.019

Caro, A. A., and Cederbaum, A. I. (2004). Oxidative stress, toxicology, and pharmacology of CYP2E1. Annu. Rev. Pharmacol. Toxicol. 44, 27-42. doi: 10.1146/annurev.pharmtox.44.101802.121704

Carter, L. G., D’Orazio, J. A., and Pearson, K. J. (2014). Resveratrol and cancer: focus on in vivo evidence. Endocr. Relat. Cancer 21, R209-R225. doi: 10.1530/ERC-13-0171

Chan, J. Y., Tan, B. K. H., and Lee, S. C. (2009). Scutellarin sensitizes drug-evoked colon cancer cell apoptosis through enhanced caspase- 6 activation. Anticancer Res. 29, 3043-3047.

Chauhan, D. P. (2002). Chemotherapeutic potential of curcumin for colorectal cancer. Curr. Pharm. Des. 8, 1695-1706. doi: 10.2174/1381612023394016

Cheah, K. Y., Howarth, G. S., Bindon, K. A., Kennedy, J. A., and Bastian, S. E. P. (2014). Low molecular weight procyanidins from grape seeds enhance the impact of 5-Fluorouracil chemotherapy on Caco-2 human colon cancer cells. PLoS ONE 9:e98921. doi: 10.1371/journal.pone.0098921

Chen, C.-C., Chow, M.-P., Huang, W.-C., Lin, Y.-C., and Chang, Y.-J. (2004). Flavonoids inhibit tumor necrosis factor-alpha-induced up-regulation of intercellular adhesion molecule-1 (ICAM-1) in respiratory epithelial cells through activator protein-1 and nuclear factor-kappaB: structure-activity relationships. Mol. Pharmacol. 66, 683-693. doi: 10.1124/mol.66.3

Chen, G., and Goeddel, D., V (2002). TNF-R1 signaling: a beautiful pathway. Science 296, 1634-1635. doi: 10.1126/science.1071924

Chen, Y. C., Yang, L. L., and Lee, T. J. F. (2000). Oroxylin A inhibition of lipopolysaccharide-induced iNOS and COX-2 gene expression via suppression of nuclear factor- kappaB activation. Biochem. Pharmacol. 59, 1445-1457. doi: 10.1016/S0006-2952(00)00255-0

Cho, H. J., Han, J., and Park, Y. (2013). Kaempferol induces cell cycle arrest in HT-29 human colon cancer cells. J. Cancer Prev. 18, 1-7. doi: 10.15430/JCP.2013.18.3.257

Chou, T. C., and Talalay, P. (1984). Quantitative analysis of dose-effect relationships: the combined effects of multiple drugs or enzyme inhibitors. $A d v$. Enzyme Regul. 22, 27-55. doi: 10.1016/0065-2571(84)90007-4

Colombo, V., Lupi, M., Falcetta, F., Forestieri, D., D'Incalci, M., and Ubezio, P. (2011). Chemotherapeutic activity of silymarin combined with doxorubicin or paclitaxel in sensitive and multidrug-resistant colon cancer cells. Cancer Chemother. Pharmacol. 67, 369-379. doi: 10.1007/s00280-010-1335-8

Colussi, D., Brandi, G., Bazzoli, F., and Ricciardiello, L. (2013). Molecular pathways involved in colorectal cancer: implications for disease behavior and prevention. Int. J. Mol. Sci. 14, 16365-16385. doi: 10.3390/ijms140816365

Darpolor, M. M., Kennealey, P. T., Le, H. C., Zakian, K. L., Ackerstaff, E., Rizwan, A., et al. (2011). Preclinical study of treatment response in HCT-116 cells and xenografts with ${ }^{1} \mathrm{H}$-decoupled ${ }^{31} \mathrm{P}$ MRS. NMR Biomed. 24, 1159-1168. doi: $10.1002 / \mathrm{nbm} .1674$ 
Dasari, S., and Tchounwou, P. B. (2014). Cisplatin in cancer therapy: molecular mechanisms of action. Eur. J. Pharmacol. 740, 364-378. doi: 10.1016/j.ejphar.2014.07.025

Del Follo-Martinez, A., Banerjee, N., Li, X., Safe, S., and Mertens-Talcott, S. (2013). Resveratrol and quercetin in combination have anticancer activity in colon cancer cells and repress oncogenic microRNA-27a. Nutr. Cancer 65, 494-504. doi: 10.1080/01635581.2012.725194

Ding, J., Polier, G., Koḧler, R., Giaisi, M., Krammer, P. H., and Li-Weber, M. (2012). Wogonin and related natural flavones overcome tumor necrosis factor-related apoptosis-inducing ligand (TRAIL) protein resistance of tumors by down-regulation of c-FLIP protein and up-regulation of TRAIL receptor 2 expression. J. Biol. Chem. 287, 641-649. doi: 10.1074/jbc.M111.2 86526

Du, B., Jiang, L., Xia, Q., and Zhong, L. (2006). Synergistic inhibitory effects of curcumin and 5-fluorouracil on the growth of the human colon cancer cell line HT-29. Chemotherapy 52, 23-28. doi: 10.1159/000090238

Du, J., Wang, Y., Chen, D., Ji, G., Ma, Q., Liao, S., et al. (2016). BAY61-3606 potentiates the anti-tumor effects of TRAIL against colon cancer through up-regulating DR4 and down-regulating NF-кB. Cancer Lett. 383, 145-153. doi: 10.1016/j.canlet.2016.10.002

Engelmann, C., Blot, E., Panis, Y., Bauer, S., Trochon, V., Nagy, H. J., et al. (2002). Apigenin - strong cytostatic and anti-angiogenic action in vitro contrasted by lack of efficacy in vivo. Phytomedicine 9, 489-495. doi: 10.1078/09447110260573100

Erdogan, S., Doganlar, O., Doganlar, Z. B., Serttas, R., Turkekul, K., Dibirdik, I., et al. (2016). The flavonoid apigenin reduces prostate cancer CD44(+) stem cell survival and migration through PI3K/Akt/NF-кB signaling. Life Sci. 162, 77-86. doi: 10.1016/j.lfs.2016.08.019

Evangelou, A. M. (2002). Vanadium in cancer treatment. Crit. Rev. Oncol. Hematol. 42, 249-265. doi: 10.1016/S1040-8428(01)00221-9

Ferlay, J., Soerjomataram, I., Dikshit, R., Eser, S., Mathers, C., Rebelo, M., et al. (2015). Cancer incidence and mortality worldwide: sources, methods and major patterns in GLOBOCAN 2012. Int. J. Cancer 136, E359-E386. doi: 10.1002/ijc. 29210

Fernández, J., Redondo-Blanco, S., Gutiérrez-del-Río, I., Miguélez, E. M., Villar, C. J., and Lombó, F. (2016). Colon microbiota fermentation of dietary prebiotics towards short-chain fatty acids and their roles as antiinflammatory and antitumour agents: a review. J. Funct. Foods 25, 511-522. doi: 10.1016/j.jff.2016.06.032

Fidler, J. M., Li, K., Chung, C., Wei, K., Ross, J. A., Gao, M., et al. (2003). PG49088 , a derivative of triptolide, causes tumor regression and sensitizes tumors to chemotherapy. Mol. Cancer Ther. 2, 855-862.

Fornier, M. N., Rathkopf, D., Shah, M., Patil, S., O'Reilly, E., Tse, A. N., et al. (2007). Phase I dose-finding study of weekly docetaxel followed by flavopiridol for patients with advanced solid tumors. Clin. Cancer Res. 13, 5841-5846. doi: 10.1158/1078-0432.CCR-07-1218

Fuchs, C. S., Moore, M. R., Harker, G., Villa, L., Rinaldi, D., and Hecht, J. R. (2003). Phase III comparison of two irinotecan dosing regimens in secondline therapy of metastatic colorectal cancer. J. Clin. Oncol. 21, 807-814. doi: $10.1200 /$ JCO.2003.08.058

Fulda, S., and Debatin, K.-M. (2004). Sensitization for anticancer drug-induced apoptosis by the chemopreventive agent resveratrol. Oncogene 23, 6702-6711. doi: 10.1038/sj.onc.1207630

Ganai, A. A., and Farooqi, H. (2015). Bioactivity of genistein: a review of in vitro and in vivo studies. Biomed. Pharmacother. 76, 30-38. doi: 10.1016/j.biopha.2015.10.026

Gao, J. L., Lv, G. Y., He, B. C., Zhang, B. Q., Zhang, H., Wang, N., et al. (2013). Ginseng saponin metabolite 20(S)-protopanaxadiol inhibits tumor growth by targeting multiple cancer signaling pathways. Oncol. Rep. 30, 292-298. doi: $10.3892 /$ or.2013.2438

Gescher, A., Steward, W. P., and Brown, K. (2013). Resveratrol in the management of human cancer: how strong is the clinical evidence? Ann. N.Y. Acad. Sci. 1290, 12-20. doi: 10.1111/nyas.12205

Goel, A., Kunnumakkara, A. B., and Aggarwal, B. B. (2008). Curcumin as "Curecumin": from kitchen to clinic. Biochem. Pharmacol. 75, 787-809. doi: 10.1016/j.bcp.2007.08.016

Gruca, A., Krawczyk, Z., Szeja, W., Grynkiewicz, G., and Rusin, A. (2014). Synthetic genistein glycosides inhibiting egfr phosphorylation enhance the effect of radiation in HCT 116 colon cancer cells. Molecules 19, 18558-18573. doi: 10.3390/molecules191118558

Guo, J., Liu, A., Cao, H., Luo, Y., Pezzuto, J. M., and van Breemen, R. B. (2008). Biotransformation of the chemopreventive agent $2^{\prime}, 4^{\prime}, 4$-trihydroxychalcone (isoliquiritigenin) by UDP-glucuronosyltransferases. Drug Metab. Dispos. 36, 2104-2112. doi: 10.1124/dmd.108.021857

Guo, J., Zhou, A., Fu, Y., Verma, U. N., Tripathy, D., Frenkel, E. P., et al. (2006). Efficacy of sequential treatment of HCT116 colon cancer monolayers and xenografts with docetaxel, flavopiridol, and 5-fluorouracil. Acta Pharmacol. Sin. 27, 1375-1381. doi: 10.1111/j.1745-7254.2006.00421.x

Gupta, S. C., Kannappan, R., Reuter, S., Kim, J. H., and Aggarwal, B. B. (2011). Chemosensitization of tumors by resveratrol. Ann. N.Y. Acad. Sci. 1215, 150-160. doi: 10.1111/j.1749-6632.2010.05852.x

Gupta, S. C., Patchva, S., and Aggarwal, B. B. (2013). Therapeutic roles of curcumin: lessons learned from clinical trials. AAPS J. 15, 195-218. doi: 10.1208/s12248-012-9432-8

Gutiérrez-del-Río, I., Villar, C. J., and Lombó, F. (2016). “Chapter 3. Therapeutic uses of kaempferol: anticancer and anti-inflammatory activity," in Kaempferol: Biosynthesis, Food Sources and Therapeutic Uses, eds T. Garde-Cerdán and A. Gonzalo-Diago (New York, NY: Nova Science Publishers), 71-100.

Ha, J., Zhao, L., Zhao, Q., Yao, J., Zhu, B.-B., Lu, N., et al. (2012). Oroxylin A improves the sensitivity of HT-29 human colon cancer cells to 5-FU through modulation of the COX-2 signaling pathway. Biochem. Cell Biol. 90, 521-531. doi: 10.1139/o2012-005

Hanif, R., Qiao, L., Shiff, S. J., and Rigas, B. (1997). Curcumin, a natural plant phenolic food additive, inhibits cell proliferation and induces cell cycle changes in colon adenocarcinoma cell lines by a prostaglandin-independent pathway. J. Lab. Clin. Med. 130, 576-584. doi: 10.1016/S0022-2143(97)90107-4

Harborne, J. B., and Williams, C. A. (2000). Advances in flavonoid research since 1992. Phytochemistry 55, 481-504. doi: 10.1016/S0031-9422(00)00235-1

Hirano, T., Oka, K., and Akiba, M. (1989). Antiproliferative effects of synthetic and naturally occurring flavonoids on tumor cells of the human breast carcinoma cell line, ZR-75-1. Res. Commun. Chem. Pathol. Pharmacol. 64, 69-78.

Ho, M. Y., and Mackey, J. R. (2014). Presentation and management of docetaxelrelated adverse effects in patients with breast cancer. Cancer Manag. Res. 6, 253-259. doi: 10.2147/CMAR.S40601

Horinaka, M., Yoshida, T., Shiraishi, T., Nakata, S., Wakada, M., and Sakai, T. (2006). The dietary flavonoid apigenin sensitizes malignant tumor cells to tumor necrosis factor-related apoptosis-inducing ligand. Mol. Cancer Ther. 5, 945-951. doi: 10.1158/1535-7163.MCT-05-0431

Hosokawa, M., Kudo, M., Maeda, H., Kohno, H., Tanaka, T., and Miyashita, K. (2004). Fucoxanthin induces apoptosis and enhances the antiproliferative effect of the PPARgamma ligand, troglitazone, on colon cancer cells. Biochim. Biophys. Acta 1675, 113-119. doi: 10.1016/j.bbagen.2004.08.012

Housman, G., Byler, S., Heerboth, S., Lapinska, K., Longacre, M., Snyder, N., et al. (2014). Drug resistance in cancer: an overview. Cancers (Basel). 6, 1769-1792. doi: $10.3390 /$ cancers6031769

Hu, X. J., Xie, M. Y., Kluxen, F. M., and Diel, P. (2014). Genistein modulates the anti-tumor activity of cisplatin in MCF-7 breast and HT-29 colon cancer cells. Arch. Toxicol. 88, 625-635. doi: 10.1007/s00204-013-1184-4

Huang, M. T., Lou, Y. R., Ma, W., Newmark, H. L., Reuhl, K. R., and Conney, A. H. (1994). Inhibitory effects of dietary curcumin on forestomach, duodenal, and colon carcinogenesis in mice. Cancer Res. 54, 5841-5847.

Huang, M.-T., Wang, Z. Y., Georgiadis, C. A., Laskin, J. D., and Conney, A. H. (1992). Inhibitory effects of curcumin on tumor initiation by benzo[a]pyrene and 7,12-dimethylbenz[a]anthracene. Carcinogenesis 13, 2183-2186. doi: 10.1093/carcin/13.11.2183

Hwang, J. T., Ha, J., and Ock, J. P. (2005). Combination of 5-fluorouracil and genistein induces apoptosis synergistically in chemo-resistant cancer cells through the modulation of AMPK and COX-2 signaling pathways. Biochem. Biophys. Res. Commun. 332, 433-440. doi: 10.1016/j.bbrc.2005.04.143

Hwang, J. T., Ha, J., Park, I. J., Lee, S. K., Baik, H. W., Kim, Y. M., et al. (2007b). Apoptotic effect of EGCG in HT-29 colon cancer cells via AMPK signal pathway. Cancer Lett. 247, 115-121. doi: 10.1016/j.canlet.2006.03.030

Hwang, J. T., Kwak, D. W., Lin, S. K., Kim, H. M., Kim, Y. M., and Park, O. J. (2007a). Resveratrol induces apoptosis in chemoresistant cancer cells via modulation of AMPK signaling pathway. Ann. N.Y. Acad. Sci. 1095, 441-448. doi: 10.1196/annals.1397.047 
Jagetia, G. C. (2007). Recent advances in indian herbal drug research guest editor: thomas paul asir devasagayam radioprotective potential of plants and herbs against the effects of ionizing radiation. J. Clin. Biochem. Nutr. 40, 74-81. doi: $10.3164 /$ jcbn. 40.74

James, M. I., Iwuji, C., Irving, G., Karmokar, A., Higgins, J. A., Griffin-Teal, N., et al. (2015). Curcumin inhibits cancer stem cell phenotypes in ex vivo models of colorectal liver metastases, and is clinically safe and tolerable in combination with FOLFOX chemotherapy. Cancer Lett. 364, 135-141. doi: 10.1016/j.canlet.2015.05.005

Jang, M., Cai, L., Udeani, G. O., Slowing, K. V., Thomas, C. F., Beecher, C. W., et al. (1997). Cancer chemopreventive activity of resveratrol, a natural product derived from grapes. Science 275, 218-220. doi: 10.1126/science.275.5297.218

Jiang, X. H., Wong, B. C., Lin, M. C., Zhu, G. H., Kung, H. F., Jiang, S. H., et al. (2001). Functional p53 is required for triptolide-induced apoptosis and AP1 and nuclear factor-kappaB activation in gastric cancer cells. Oncogene 20, 8009-8018. doi: $10.1038 /$ sj.onc. 1204981

Jin, H., Gong, W., Zhang, C., and Wang, S. (2013). Epigallocatechin gallate inhibits the proliferation of colorectal cancer cells by regulating Notch signaling. Onco Targets Ther. 6, 145-153. doi: 10.2147/OTT.S40914

Jin, Y. H., Choi, J. S., Shin, S., Lee, K. Y., Park, J. H., and Lee, S. K. (2003). Panaxadiol selectively inhibits cyclin A-associated Cdk2 activity by elevating p21WAF1/CIP1 protein levels in mammalian cells. Carcinogenesis 24, 1767-1772. doi: 10.1093/carcin/bgg097

Jung, G. R., Kim, K. J., Choi, C. H., Lee, T. B., Han, S. I., Han, H. K., et al. (2007). Effect of betulinic acid on anticancer drug-resistant colon cancer cells. Basic Clin. Pharmacol. Toxicol. 101, 277-285. doi: 10.1111/j.1742-7843.2007.00115.x

Kaminski, B. M., Weigert, A., Scherzberg, M.-C., Ley, S., Gilbert, B., Brecht, K., et al. (2014). Resveratrol-induced potentiation of the antitumor effects of oxaliplatin is accompanied by an altered cytokine profile of human monocyte-derived macrophages. Apoptosis 19, 1136-1147. doi: 10.1007/s10495-014-0988-x

Kantara, C., O'Connell, M., Sarkar, S., Moya, S., Ullrich, R., and Singh, P. (2014). Curcumin promotes autophagic survival of a subset of colon cancer stem cells, which are ablated by DCLK1-siRNA. Cancer Res. 74, 2487-2498. doi: 10.1158/0008-5472.CAN-13-3536

Karin, M., Yamamoto, Y., and Wang, Q. M. (2004). The IKK NF-kappa B system: a treasure trove for drug development. Nat. Rev. Drug Discov. 3, 17-26. doi: $10.1038 / \operatorname{nrd} 1279$

Kasala, E. R., Bodduluru, L. N., Madana, R. M., V, A. K., Gogoi, R., and Barua, C. C. (2015). Chemopreventive and therapeutic potential of chrysin in cancer: mechanistic perspectives. Toxicol. Lett. 233, 214-225. doi: 10.1016/j.toxlet.2015.01.008

Katayama, K., Masuyama, K., Yoshioka, S., Hasegawa, H., Mitsuhashi, J., and Sugimoto, Y. (2007). Flavonoids inhibit breast cancer resistance protein-mediated drug resistance: transporter specificity and structureactivity relationship. Cancer Chemother. Pharmacol. 60, 789-797. doi: 10.1007/s00280-007-0426-7

Kawamori, T., Lubet, R., Steele, V. E., Kelloff, G. J., Kaskey, R. B., Rao, C. V., et al. (1999). Chemopreventive effect of curcumin, a naturally occurring antiinflammatory agent, during the promotion/progression stages of colon cancer. Cancer Res. 59, 597-601.

Kelland, L. R. (2000). Flavopiridol, the first cyclin-dependent kinase inhibitor to enter the clinic: current status. Expert Opin. Investig. Drugs 9, 2903-2911. doi: 10.1517/13543784.9.12.2903

Khan, R., Khan, A. Q., Qamar, W., Lateef, A., Tahir, M., Rehman, M. U., et al. (2012). Chrysin protects against cisplatin-induced colon. toxicity via amelioration of oxidative stress and apoptosis: probable role of p38MAPK and p53. Toxicol. Appl. Pharmacol. 258, 315-329. doi: 10.1016/j.taap.2011.11.013

Kim, J. M., Araki, S., Kim, D. J., Park, C. B., Takasuka, N., Baba-Toriyama, H., et al. (1998). Chemopreventive effects of carotenoids and curcumins on mouse colon carcinogenesis after 1,2-dimethylhydrazine initiation. Carcinogenesis 19, 81-85. doi: 10.1093/carcin/19.1.81

Kim, S. M., Lee, S. Y., Yuk, D. Y., Moon, D. C., Choi, S. S., Kim, Y., et al. (2009). Inhibition of NF-kB by ginsenoside Rg3 enhances the susceptibility of colon cancer cells to docetaxel. Arch. Pharm. Res. 32, 755-765. doi: 10.1007/s12272-009-1515-4

Klein-Marcuschamer, D., Ajikumar, P. K., and Stephanopoulos, G. (2007). Engineering microbial cell factories for biosynthesis of isoprenoid molecules: beyond lycopene. Trends Biotechnol. 25, 417-424. doi: 10.1016/j.tibtech.2007.07.006

Koh, S. J., Tak, J. K., Kim, S. T., Nam, W. S., Kim, S. Y., Park, K. M., et al. (2012). Sensitization of ionizing radiation-induced apoptosis by ursolic acid. Free Radic. Res. 46, 339-345. doi: 10.3109/10715762.2012.656101

Kumar, S., and Pandey, A. K. (2007). Chemistry and biological activities of flavonoids: an overview. Sci. World J. 73, 637-670. doi: 10.1155/2013/162750

Kumar, S., and Pandey, A. K. (2013). Chemistry and biological activities of flavonoids: an overview. Sci.World J. 2013:162750. doi: 10.1155/2013/162750

Kumazaki, M., Noguchi, S., Yasui, Y., Iwasaki, J., Shinohara, H., Yamada, N., et al. (2013). Anti-cancer effects of naturally occurring compounds through modulation of signal transduction and miRNA expression in human colon cancer cells. J. Nutr. Biochem. 24, 1849-1858. doi: 10.1016/j.jnutbio.2013.04.006 Kunnumakkara, A. B., Diagaradjane, P., Anand, P., Kuzhuvelil, H. B., Deorukhkar, A., Gelovani, J., et al. (2009). Curcumin sensitizes human colorectal cancer to capecitabine by modulation of cyclin D1, COX-2, MMP-9, VEGF and CXCR4 expression in an orthotopic mouse model. Int. J. Cancer 125, 2187-2197. doi: $10.1002 / \mathrm{ijc} .24593$

Lan, L., Appelman, C., Smith, A. R., Yu, J., Larsen, S., Marquez, R. T., et al. (2015). Natural product (-)-gossypol inhibits colon cancer cell growth by targeting RNA-binding protein Musashi-1. Mol. Oncol. 9, 1406-1420. doi: 10.1016/j.molonc.2015.03.014

Lee, C. K., Son, S. H., Park, K. K., Park, J. H. Y., Lim, S. S., and Chung, W. Y. (2008). Isoliquiritigenin inhibits tumor growth and protects the kidney and liver against chemotherapy-induced toxicity in a mouse xenograft model of colon carcinoma. J. Pharmacol. Sci. 106, 444-451. doi: 10.1254/jphs.FP0071498

Lee, H. S., Cho, H. J., Kwon, G. T., Han, J., and Park, Y. (2014a). Kaempferol Downregulates Insulin-like growth factor-I receptor and ErbB3 signaling in HT-29 human colon cancer cells. J. Cancer Prev. 19, 161-169. doi: 10.15430/JCP.2014.19.3.161

Lee, H. S., Cho, H. J., Yu, R., Lee, K. W., Chun, H. S., and Park, J. H. Y. (2014b). Mechanisms underlying apoptosis-inducing effects of kaempferol in HT-29 human colon cancer cells. Int. J. Mol. Sci. 15, 2722-2737. doi: $10.3390 / \mathrm{ijms} 15022722$

Lee, J. I., Hsu, B. H., Wu, D., and Barrett, J. S. (2006). Separation and characterization of silybin, isosilybin, silydianin and silychristin in milk thistle extract by liquid chromatography-electrospray tandem mass spectrometry. J. Chromatogr. A 1116, 57-68. doi: 10.1016/j.chroma.2006.03.053

Lee, Y., Sung, B., Kang, Y. J., Kim, D. H., Jang, J. Y., Hwang, S. Y., et al. (2014). Apigenin-induced apoptosis is enhanced by inhibition of autophagy formation in HCT116 human colon cancer cells. Int. J. Oncol. 44, 1599-1606. doi: $10.3892 /$ ijo. 2014.2339

Lefort, É. C., and Blay, J. (2011). The dietary flavonoid apigenin enhances the activities of the anti-metastatic protein CD26 on human colon carcinoma cells. Clin. Exp. Metastasis 28, 337-349. doi: 10.1007/s10585-010-9364-6

León, I. E., Cadavid-Vargas, J. F., Tiscornia, I., Porro, V., Castelli, S., Katkar, P., et al. (2015). Oxidovanadium(IV) complexes with chrysin and silibinin: anticancer activity and mechanisms of action in a human colon adenocarcinoma model. J. Biol. Inorg. Chem. 20, 1175-1191. doi: 10.1007/s00775-015-1298-7

Li, L., Ahmed, B., Mehta, K., and Kurzrock, R. (2007). Liposomal curcumin with and without oxaliplatin: effects on cell growth, apoptosis, and angiogenesis in colorectal cancer. Mol. Cancer Ther. 6, 1276-1282. doi: 10.1158/1535-7163.MCT-06-0556

Li, W., Du, B., Wang, T., Wang, S., and Zhang, J. (2009). Kaempferol induces apoptosis in human HCT116 colon cancer cells via the Ataxia-Telangiectasia mutated-p53 pathway with the involvement of p53 upregulated modulator of apoptosis. Chem. Biol. Interact. 177, 121-127. doi: 10.1016/j.cbi.2008.10.048

Li, X., Huang, Q., Ong, C.-N., Yang, X.-F., and Shen, H.-M. (2010). Chrysin sensitizes tumor necrosis factor- $\alpha$-induced apoptosis in human tumor cells via suppression of nuclear factor-kappaB. Cancer Lett. 293, 109-116. doi: 10.1016/j.canlet.2010.01.002

Li, X. L., Wang, C. Z., Mehendale, S. R., Sun, S., Wang, Q., and Yuan, C. S. (2009). Panaxadiol, a purified ginseng component, enhances the anti-cancer effects of 5-fluorouracil in human colorectal cancer cells. Cancer Chemother. Pharmacol. 64, 1097-1104. doi: 10.1007/s00280-009-0966-0

Liu, W. M., Gravett, A. M., and Dalgleish, A. G. (2011). The antimalarial agent artesunate possesses anticancer properties that can be enhanced by combination strategies. Int. J. Cancer 128, 1471-1480. doi: 10.1002/ijc.25707 
Liu, Y., Xiao, E., Yuan, L., and Li, G. (2014). Triptolide synergistically enhances antitumor activity of oxaliplatin in colon carcinoma in vitro and in vivo. DNA Cell Biol. 33, 418-425. doi: 10.1089/dna.2014.2356

Luo, Y., Wang, S.-X., Zhou, Z.-Q., Wang, Z., Zhang, Y.-G., Zhang, Y., et al. (2014). Apoptotic effect of genistein on human colon cancer cells via inhibiting the nuclear factor-kappa B (NF-B) pathway. Tumour Biol. 35, 11483-11488. doi: $10.1007 /$ s13277-014-2487-7

Majumdar, A. P. N., Banerjee, S., Nautiyal, J., Patel, B. B., Patel, V., Du, J., et al. (2009). Curcumin synergizes with resveratrol to inhibit colon cancer. Nutr. Cancer 61, 544-553. doi: 10.1080/01635580902752262

Manach, C., Scalbert, A., Morand, C., Rémésy, C., and Jiménez, L. (2004). Polyphenols: food sources and bioavailability. Am. J. Clin. Nutr. 79, 727-747.

Marín, L., Miguélez, E. M., Villar, C. J., and Lombó, F. (2015). Bioavailability of dietary polyphenols and gut microbiota metabolism: antimicrobial properties. Biomed Res. Int. 2015:905215. doi: 10.1155/2015/905215

Merrill, R. M., and Anderson, A. E. (2011). Risk-adjusted colon and rectal cancer incidence rates in the United States. Dis. Colon Rectum 54, 1301-1306. doi: 10.1097/DCR.0b013e3182242bd3

Mertens-Talcott, S. U., and Percival, S. S. (2005). Ellagic acid and quercetin interact synergistically with resveratrol in the induction of apoptosis and cause transient cell cycle arrest in human leukemia cells. Cancer Lett. 218, 141-151. doi: 10.1016/j.canlet.2004.06.007

Meshnick, S. R. (2002). Artemisinin: mechanisms of action, resistance and toxicity. Int. J. Parasitol. 32, 1655-1660. doi: 10.1016/S0020-7519(02)00194-7

Misawa, N. (2011). Pathway engineering for functional isoprenoids. Curr. Opin. Biotechnol. 22, 627-633. doi: 10.1016/j.copbio.2011.01.002

Miyamoto, S., Kohno, H., Suzuki, R., Sugie, S., Murakami, A., Ohigashi, H., et al. (2006). Preventive effects of chrysin on the development of azoxymethaneinduced colonic aberrant crypt foci in rats. Oncol. Rep. 15, 1169-1173. doi: 10.3892/or.15.5.1169

Miyamoto, S., Yasui, Y., Ohigashi, H., Tanaka, T., and Murakami, A. (2010). Dietary flavonoids suppress azoxymethane-induced colonic preneoplastic lesions in male C57BL/KsJ-db/db mice. Chem. Biol. Interact. 183, 276-283. doi: 10.1016/j.cbi.2009.11.002

Mizushina, Y., Shiomi, K., Kuriyama, I., Takahashi, Y., and Yoshida, H. (2013). Inhibitory effects of a major soy isoflavone, genistein, on human DNA topoisomerase II activity and cancer cell proliferation. Int. J. Oncol. 43, 1117-1124. doi: 10.3892/ijo.2013.2032

Mohapatra, P., Preet, R., Choudhuri, M., Choudhuri, T., and Kundu, C. N. (2011). 5 -fluorouracil increases the chemopreventive potentials of resveratrol through DNA damage and MAPK signaling pathway in human colorectal cancer cells. Oncol. Res. 19, 311-321. doi: 10.3727/096504011X13079697132844

Morin, P. J., Sparks, A. B., Korinek, V., Barker, N., Clevers, H., Vogelstein, B., et al. (1997). Activation of beta-catenin-Tcf signaling in colon cancer by mutations in beta-catenin or APC. Science 275, 1787-1790. doi: $10.1126 /$ science. 275.5307 .1787

Morris, J., Moseley, V. R., Cabang, A. B., Coleman, K., Wei, W., GarrettMayer, E., et al. (2016). Reduction in promotor methylation utilizing EGCG (Epigallocatechin-3-gallate) restores RXRalpha expression in human colon cancer cells. Oncotarget 7, 11-17. doi: 10.18632/oncotarget.9204

Moseley, V. R., Morris, J., Knackstedt, R. W., and Wargovich, M. J. (2013). Green tea polyphenol epigallocatechin 3-gallate, contributes to the degradation of DNMT3A and HDAC3 in HCT 116 human colon cancer cells. Anticancer Res. 33, 5325-5334.

Motwani, M., Jung, C., Sirotnak, F. M., She, Y., Shah, M. A., Gonen, M., et al. (2001). Augmentation of apoptosis and tumor regression by flavopiridol in the presence of CPT-11 in Hct116 colon cancer monolayers and xenografts. Clin. Cancer Res. 7, 4209-4219.

Murakami, A., Furukawa, I., Miyamoto, S., Tanaka, T., and Ohigashi, H. (2013). Curcumin combined with turmerones, essential oil components of turmeric, abolishes inflammation-associated mouse colon carcinogenesis. Biofactors 39, 221-232. doi: 10.1002/biof.1054

Nautiyal, J., Kanwar, S. S., Yu, Y., and Majumdar, A. P. (2011). Combination of dasatinib and curcumin eliminates chemo-resistant colon cancer cells. J. Mol. Signal. 6:7. doi: 10.1186/1750-2187-6-7

Newcomb, E. W. (2004). Flavopiridol: pleiotropic biological effects enhance its anti-cancer activity. Anticancer Drugs 15, 411-419. doi: 10.1097/01.cad.0000127332.06439.47
Ohishi, T., Kishimot, Y., Hara, Y., Hasegawa, J., and Isemura, M. (2002). Synergistic effects of (-)-epigallocatechin gallate with sulindac against colon carcinogenesis of rats treated with azoxymethane. Cancer Lett. 177, 118-121. doi: 10.1016/S0304-3835(01)00767-4

Osman, N. H. A., Said, U. Z., El-Waseef, A. M., and Ahmed, E. S. A. (2015). Luteolin supplementation adjacent to aspirin treatment reduced dimethylhydrazine-induced experimental colon carcinogenesis in rats. Tumour Biol. 36, 1179-1190. doi: 10.1007/s13277-014-2678-2

Pampaloni, B., Palmini, G., Mavilia, C., Zonefrati, R., Tanini, A., and Brandi, M. L. (2014). In vitro effects of polyphenols on colorectal cancer cells. World J. Gastrointest. Oncol. 6, 289-300. doi: 10.4251/wjgo.v6.i8.289

Pan, M.-H., Lai, C.-S., Wu, J.-C., and Ho, C.-T. (2011). Molecular mechanisms for chemoprevention of colorectal cancer by natural dietary compounds. Mol. Nutr. Food Res. 55, 32-45. doi: 10.1002/mnfr.201000412

Park, J. H., Oh, E. J., Choi, Y. H., Kang, C. D., Kang, H. S., Kim, D. K., et al. (2001). Synergistic effects of dexamethasone and genistein on the expression of Cdk inhibitor p21WAF1/CIP1 in human hepatocellular and colorectal carcinoma cells. Int. J. Oncol. 18, 997-1002. doi: 10.3892/ijo.18.5.997

Park, M. T., Cha, H. J., Jeong, J. W., Kim, S. I., Chung, H. Y., Kim, N. D., et al. (1999). Glucocorticoid receptor-induced down-regulation of MMP-9 by ginseng components, PD and PT contributes to inhibition of the invasive capacity of HT1080 human fibrosarcoma cells. Mol. Cells 9, 476-483.

Patel, B. B., Sengupta, R., Qazi, S., Vachhani, H., Yu, Y., Rishi, A. K., et al. (2008). Curcumin enhances the effects of 5-fluorouracil and oxaliplatin in mediating growth inhibition of colon cancer cells by modulating EGFR and IGF-1R. Int. J. Cancer 122, 267-273. doi: 10.1002/ijc.23097

Patel, K. R., Brown, V. A., Jones, D. J. L., Britton, R. G., Hemingway, D., Miller, A. S., et al. (2010). Clinical pharmacology of resveratrol and its metabolites in colorectal cancer patients. Cancer Res. 70, 7392-7399. doi: 10.1158/0008-5472.CAN-10-2027

Pavlidis, E. T., and Pavlidis, T. E. (2013). Role of bevacizumab in colorectal cancer growth and its adverse effects: a review. World J. Gastroenterol. 19, 5051-5060. doi: 10.3748/wjg.v19.i31.5051

Perkins, S., Verschoyle, R. D., Hill, K., Parveen, I., Threadgill, M. D., Sharma, R. A., et al. (2002). Chemopreventive efficacy and pharmacokinetics of curcumin in the $\mathrm{min} /+$ mouse, a model of familial adenomatous polyposis. Cancer Epidemiol. Biomarkers Prev. 11, 535-540.

Poindessous, V., Koeppel, F., Raymond, E., Cvitkovic, E., Waters, S. J., and Larsen, A. K. (2003). Enhanced antitumor activity of irofulven in combination with 5fluorouracil and cisplatin in human colon and ovarian carcinoma cells. Int. J. Oncol. 23, 1347-1355. doi: 10.3892/ijo.23.5.1347

Prasad, S., Tyagi, A. K., and Aggarwal, B. B. (2014). Recent developments in delivery, bioavailability, absorption and metabolism of curcumin: the golden pigment from golden spice. Cancer Res. Treat. 46, 2-18. doi: 10.4143/crt.2014.46.1.2

Prasad, S., Yadav, V. R., Sung, B., Reuter, S., Kannappan, R., Deorukhkar, A., et al. (2012). Ursolic acid inhibits growth and metastasis of human, colorectal cancer in an orthotopic nude mouse model by targeting multiple cell signaling pathways: chemosensitization with capecitabine. Clin. Cancer Res. 18, 4942-4953. doi: 10.1158/1078-0432.CCR-11-2805

Psahoulia, F. H., Drosopoulos, K. G., Doubravska, L., Andera, L., and Pintzas, A. (2007). Quercetin enhances TRAIL-mediated apoptosis in colon cancer cells by inducing the accumulation of death receptors in lipid rafts. Mol. Cancer Ther. 6, 2591-2599. doi: 10.1158/1535-7163.MCT-07-0001

Ranelletti, F. O., Maggiano, N., Serra, F. G., Ricci, R., Larocca, L. M., Lanza, P., et al. (2000). Quercetin inhibits p21-RAS expression in human colon cancer cell lines and in primary colorectal tumors. Int. J. Cancer 85, 438-445. doi: 10.1002/(SICI)1097-0215(20000201)85:3<438::AID-IJC22>3. $0 . \mathrm{CO} ; 2-\mathrm{F}$

Rao, C. V., Simi, B., and Reddy, B. S. (1993). Inhibition by dietary curcumin of azoxymethane-induced ornithine decarboxylase, tyrosine protein kinase, arachidonic acid metabolism and aberrant crypt foci formation in the rat colon. Carcinogenesis 14, 2219-2225. doi: 10.1093/carcin/14.11.2219

Ravindran, J., Prasad, S., and Aggarwal, B. B. (2009). Curcumin and cancer cells: how many ways can curry kill tumor cells selectively? AAPS J. 11, 495-510. doi: 10.1208/s12248-009-9128-x

Reddivari, L., Charepalli, V., Radhakrishnan, S., Vadde, R., Elias, R. J., Lambert, J. D., et al. (2016). Grape compounds suppress colon cancer stem cells in vitro 
and in a rodent model of colon carcinogenesis. BMC Complement. Altern. Med. 16:278. doi: 10.1186/s12906-016-1254-2

Renuka, M., Vijayakumar, N., and Ramakrishnan, A. (2016). Chrysin, a flavonoid attenuates histological changes of hyperammonemic rats: a dose dependent study. Biomed. Pharmacother. 82, 345-354. doi: 10.1016/j.biopha.2016.05.013

Romier, B., Van De Walle, J., During, A., Larondelle, Y., and Schneider, Y.-J. (2008). Modulation of signalling nuclear factor-kappaB activation pathway by polyphenols in human intestinal Caco-2 cells. Br. J. Nutr. 100, 542-551. doi: $10.1017 /$ S0007114508966666

Ronnekleiv-Kelly, S. M., Geiger, P. G., and Kennedy, G. D. (2012). Chrysin activates the aryl hydrocarbon receptor and reduces colon cancer cell viability. J. Surg. Res. 172:305. doi: 10.1016/j.jss.2011.11.536

Rossi, M., Negri, E., Talamini, R., Bosetti, C., Parpinel, M., Gnagnarella, P., et al. (2006). Flavonoids and colorectal cancer in Italy. Cancer Epidemiol. Biomarkers Prev. 15, 1555-1558. doi: 10.1158/1055-9965.EPI-06-0017

Rotches-Ribalta, M., Andres-Lacueva, C., Estruch, R., Escribano, E., and UrpiSarda, M. (2012). Pharmacokinetics of resveratrol metabolic profile in healthy humans after moderate consumption of red wine and grape extract tablets. Pharmacol. Res. 66, 375-382. doi: 10.1016/j.phrs.2012.08.001

Saldanha, S. N., Kala, R., and Tollefsbol, T. O. (2014). Molecular mechanisms for inhibition of colon cancer cells by combined epigenetic-modulating epigallocatechin gallate and sodium butyrate. Exp. Cell Res. 324, 40-53. doi: 10.1016/j.yexcr.2014.01.024

Santandreu, F. M., Valle, A., Oliver, J., and Roca, P. (2011). Resveratrol potentiates the cytotoxic oxidative stress induced by chemotherapy in human colon cancer cells. Cell. Physiol. Biochem. 28, 219-228. doi: 10.1159/000331733

Serova, M., Calvo, F., Lokiec, F., Koeppel, F., Poindessous, V., Larsen, A. K., et al. (2006). Characterizations of irofulven cytotoxicity in combination with cisplatin and oxaliplatin in human colon, breast, and ovarian cancer cells. Cancer Chemother. Pharmacol. 57, 491-499. doi: 10.1007/s00280-005-0063-y

Shao, H., Jing, K., Mahmoud, E., Huang, H., Fang, X., and Yu, C. (2013). Apigenin sensitizes colon cancer cells to antitumor activity of ABT-263. Mol. Cancer Ther. 12, 2640-2650. doi: 10.1158/1535-7163.MCT-13-0066

Shi, M.-D., Shiao, C.-K., Lee, Y.-C., and Shih, Y.-W. (2015). Apigenin, a dietary flavonoid, inhibits proliferation of human bladder cancer T-24 cells via blocking cell cycle progression and inducing apoptosis. Cancer Cell Int. 15:33. doi: 10.1186/s12935-015-0186-0

Shimizu, M., Deguchi, A., Lim, J. E., Moriwaki, H., Kopelovich, L., and Weinstein, I. B. (2005). (-)-Epigallocatechin gallate and polyphenon e inhibit growth and activation of the epidermal growth factor receptor and human epidermal growth factor receptor-2 signaling pathways in human colon cancer cells. Clin. Cancer Res. 11, 2735-2746. doi: 10.1158/1078-0432.ccr-04-2014

Singh, B. N., Shankar, S., and Srivastava, R. K. (2011). Green tea catechin, epigallocatechin-3-gallate (EGCG): mechanisms, perspectives and clinical applications. Biochem. Pharmacol. 82, 1807-1821. doi: $10.1016 /$ j.bcp.2011.07.093

Singh, C. K., George, J., and Ahmad, N. (2013). Resveratrol-based combinatorial strategies for cancer management. Ann. N.Y. Acad. Sci. 1290, 113-121. doi: $10.1111 /$ nyas. 12160

Singh, D., Attri, B. K., Gill, R. K., and Bariwal, J. (2016). Review on EGFR inhibitors: critical updates. Mini Rev. Med. Chem. 16, 1134-1166. doi: 10.2174/1389557516666160321114917

Son, T., Gong, E., Bae, M., Kim, S., Heo, K., Moon, C., et al. (2013). Protective effect of genistein on radiation-induced intestinal injury in tumor bearing mice. $B M C$ Complement. Altern. Med. 13:103. doi: 10.1186/1472-6882-13-103

Sparks, A. B., Morin, P. J., Vogelstein, B., and Kinzler, K. W. (1998). Mutational analysis of the APC/beta-catenin/Tcf pathway in colorectal cancer. Cancer Res. $58,1130-1134$.

Spector, D., Anthony, M., Alexander, D., and Arab, L. (2003). Soy consumption and colorectal cancer. Nutr. Cancer 47, 1-12. doi: 10.1207/s15327914nc4701_1

Srimuangwong, K., Tocharus, C., Chintana, P. Y., Suksamrarn, A., and Tocharus, J. (2012a). Hexahydrocurcumin enhances inhibitory effect of 5-fluorouracil on HT-29 human colon cancer cells. World J. Gastroenterol. 18, 2383-2389. doi: 10.3748/wjg.v18.i19.2383

Srimuangwong, K., Tocharus, C., Tocharus, J., Suksamrarn, A., and Chintana, P. Y. (2012b). Effects of hexahydrocurcumin in combination with 5-fuorouracil on dimethylhydrazine-induced colon cancer in rats. World J. Gastroenterol. 18, 6951-6959. doi: 10.3748/wjg.v18.i47.6951
Suganuma, M., Okabe, S., Kai, Y., Sueoka, N., Sueoka, E., and Fujiki, H. (1999). Synergistic effects of (-)-epigallocatechin gallate with (-)-epicatechin, sulindac, or tamoxifen on cancer-preventive activity in the human lung cancer cell line PC-9. Cancer Res. 59, 44-47.

Takada, Y., and Aggarwal, B. B. (2004). Flavopiridol inhibits NF-kappaB activation induced by various carcinogens and inflammatory agents through inhibition of IkappaBalphakinase and p65 phosphorylation. Abrogation of cyclin D1, cyclooxygenase-2, and matrix metalloprotease-9. J. Biol. Chem. 279, 4750-4759. doi: $10.1074 /$ jbc.M304546200

Tallarida, R. J. (2002). The interaction index: a measure of drug synergism. Pain 98, 163-168. doi: 10.1016/S0304-3959(02)00041-6

Tang, X., Zhu, Y., Tao, W., Wei, B., and Lin, X. (2007). Synergistic effect of triptolide combined with 5-fluorouracil on colon carcinoma. Postgrad. Med. J. 83, 338-343. doi: 10.1136/pgmj.2006.055426

Thorn, C. F., Oshiro, C., Marsh, S., Hernandez-Boussard, T., McLeod, H., Klein, T. E., et al. (2011). Doxorubicin pathways: pharmacodynamics and adverse effects. Pharmacogenet. Genomics 21, 440-446. doi: 10.1097/FPC.0b013e32833ffb56

Tolba, M. F., and Abdel-Rahman, S. Z. (2015). Pterostilbine, an active component of blueberries, sensitizes colon cancer cells to 5-fluorouracil cytotoxicity. Sci. Rep. 5:15239. doi: 10.1038/srep15239

Tolcher, A. W., LoRusso, P., Arzt, J., Busman, T. A., Lian, G., Rudersdorf, N. S., et al. (2015). Safety, efficacy, and pharmacokinetics of navitoclax (ABT-263) in combination with irinotecan: results of an open-label, phase 1 study. Cancer Chemother. Pharmacol. 76, 1041-1049. doi: 10.1007/s00280-015$2882-9$

Tsai, C.-C., Chuang, T.-W., Chen, L.-J., Niu, H.-S., Chung, K.-M., Cheng, J.-T., et al. (2015). Increase in apoptosis by combination of metformin with silibinin in human colorectal cancer cells. World J. Gastroenterol. 21, 4169-4177. doi: 10.3748/wjg.v21.i14.4169

Tsai, Y. M., Chien, C. F., Lin, L. C., and Tsai, T. H. (2011). Curcumin and its nano-formulation: the kinetics of tissue distribution and blood-brain barrier penetration. Int. J. Pharm. 416, 331-338. doi: 10.1016/j.ijpharm.2011.06.030

van der Stok, E. P., Spaander, M. C. W., Grünhagen, D. J., Verhoef, C., and Kuipers, E. J. (2016). Surveillance after curative treatment for colorectal cancer. Nat. Rev. Clin. Oncol. doi: 10.1038/nrclinonc.2016.199. [Epub ahead of print].

Vieira, A., Heidor, R., Cardozo, M. T., Scolastici, C., Purgatto, E., Shiga, T. M., et al. (2011). Efficacy of geraniol but not of $\beta$-ionone or their combination for the chemoprevention of rat colon carcinogenesis. Brazilian J. Med. Biol. Res. 44, 538-545. doi: 10.1590/S0100-879X2011000600007

Walle, T., Hsieh, F., DeLegge, M. H., Oatis, J. E., and Walle, U. K. (2004). High absorption but very low bioavailability of oral resveratrol in humans. Drug Metab. Dispos. 32, 1377-1382. doi: 10.1124/dmd.104.000885

Wang, C. Z., Luo, X., Zhang, B., Song, W. X., Ni, M., Mehendale, S., et al. (2007a). Notoginseng enhances anti-cancer effect of 5-fluorouracil on human colorectal cancer cells. Cancer Chemother. Pharmacol. 60, 69-79. doi: 10.1007/s00280-006-0350-2

Wang, C. Z., Xie, J. T., Zhang, B., Ni, M., Fishbein, A., Aung, H. H., et al. (2007b). Chemopreventive effects of Panax notoginseng and its major constituents on SW480 human colorectal cancer cells. Int. J. Oncol. 31, 1149-1156.

Wang, C. Z., Zhang, Z., Wan, J. Y., Zhang, C. F., Anderson, S., He, X., et al. (2015). Protopanaxadiol, an active ginseng metabolite, significantly enhances the effects of fluorouracil on colon cancer. Nutrients 7, 799-814. doi: 10.3390/nu7020799

Wang, W., VanAlstyne, P. C., Irons, K. A., Chen, S., Stewart, J. W., and Birt, D. F. (2004). Individual and interactive effects of apigenin analogs on G2/M cellcycle arrest in human colon carcinoma cell lines. Nutr. Cancer 48, 106-114. doi: 10.1207/s15327914nc4801_14

Wubetu, G. Y., Shimada, M., Morine, Y., Ikemoto, T., Ishikawa, D., Iwahashi, S., et al. (2015). Epigallocatechin gallate hinders human hepatoma and colon cancer sphere formation. J. Gastroenterol. Hepatol. 31, 256-264. doi: 10.1111 /jgh.13069

Xavier, C. P. R., Lima, C. F., Rohde, M., and Pereira-Wilson, C. (2011). Quercetin enhances 5-fluorouracil-induced apoptosis in MSI colorectal cancer cells through p53 modulation. Cancer Chemother. Pharmacol. 68, 1449-1457. doi: 10.1007/s00280-011-1641-9

Xiao, X., Liu, Z., Wang, R., Wang, J., Zhang, S., Cai, X., et al. (2015). Genistein suppresses FLT4 and inhibits human colorectal cancer metastasis. Oncotarget 6, 3225-3239. doi: 10.18632/oncotarget.3064 
Xing, J., You, H., Dong, Y., Lu, J., Chen, S., Zhu, H., et al. (2011). Metabolic and pharmacokinetic studies of scutellarin in rat plasma, urine, and feces. Acta Pharmacol. Sin. 32, 655-663. doi: 10.1038/aps.2011.11

Yallapu, M. M., Jaggi, M., and Chauhan, S. C. (2012). Curcumin nanoformulations: a future nanomedicine for cancer. Drug Discov. Today 17, 71-80. doi: 10.1016/j.drudis.2011.09.009

Yang, D., Qu, J., Qu, X., Cao, Y., Xu, L., Hou, K., et al. (2015). Gossypol sensitizes the antitumor activity of 5-FU through down-regulation of thymidylate synthase in human colon carcinoma cells. Cancer Chemother. Pharmacol. 76, 575-586. doi: 10.1007/s00280-015-2749-0

Yang, L., Allred, K. F., Dykes, L., Allred, C. D., and Awika, J. M. (2015). Enhanced action of apigenin and naringenin combination on estrogen receptor activation in non-malignant colonocytes: implications on sorghum-derived phytoestrogens. Food Funct. 6, 749-755. doi: 10.1039/C4FO00300D

Yang, M. H., Kim, J., Khan, I. A., Walker, L. A., and Khan, S. I. (2014). Nonsteroidal anti-inflammatory drug activated gene-1 (NAG-1) modulators from natural products as anti-cancer agents. Life Sci. 100, 75-84. doi: 10.1016/j.lfs.2014.01.075

Yang, S., Li, W., Sun, H., Wu, B., Ji, F., Sun, T., et al. (2015). Resveratrol elicits anticolorectal cancer effect by activating miR-34c-KITLG in vitro and in vivo. BMC Cancer 15:969. doi: 10.1186/s12885-015-1958-6

Yoshida, T., Konishi, M., Horinaka, M., Yasuda, T., Goda, A. E., Taniguchi, H., et al. (2008). Kaempferol sensitizes colon cancer cells to TRAIL-induced apoptosis. Biochem. Biophys. Res. Commun. 375, 129-133. doi: 10.1016/j.bbrc.2008.07.131

Yu, Z., Li, W., and Liu, F. (2004). Inhibition of proliferation and induction of apoptosis by genistein in colon cancer HT-29 cells. Cancer Lett. 215, 159-166. doi: 10.1016/j.canlet.2004.06.010

Yue, G. G. L., Jiang, L., Kwok, H. F., Lee, J. K. M., Chan, K. M., Fung, K. P., et al. (2016b). Turmeric ethanolic extract possesses stronger inhibitory activities on colon tumour growth than curcumin - the importance of turmerones. J. Funct. Foods 22, 565-577. doi: 10.1016/j.jff.2016.02.011

Yue, G. G. L., Kwok, H.-F., Lee, J. K.-M., Jiang, L., Wong, E. C.-W., Gao, S., et al. (2016a). Combined therapy using bevacizumab and turmeric ethanolic extract (with absorbable curcumin) exhibited beneficial efficacy in colon cancer mice. Pharmacol. Res. 111, 43-57. doi: 10.1016/j.phrs.2016.05.025

Zhang, M., Liu, H., Guo, R., Ling, Y., Wu, X., Li, B., et al. (2003). Molecular mechanism of gossypol-induced cell growth inhibition and cell death of HT-29 human colon carcinoma cells. Biochem. Pharmacol. 66, 93-103. doi: 10.1016/S0006-2952(03)00248-X

Zhang, Y., Li, Q., Zhou, D., and Chen, H. (2013). Genistein, a soya isoflavone, prevents azoxymethane-induced up-regulation of $\mathrm{WNT} / \beta$-catenin signalling and reduces colon pre-neoplasia in rats. Br. J. Nutr. 109, 33-42. doi: $10.1017 /$ S0007114512000876

Zhong, Y., Krisanapun, C., Lee, S. H., Nualsanit, T., Sams, C., Peungvicha, P., et al. (2010). Molecular targets of apigenin in colorectal cancer cells: involvement of p21, NAG-1 and p53. Eur. J. Cancer 46, 3365-3374. doi: 10.1016/j.ejca.2010.07.007

Zhou, F., Zhou, H., Wang, T., Mu, Y., Wu, B., Guo, D., et al. (2012). Epigallocatechin-3-gallate inhibits proliferation and migration of human colon cancer SW620 cells in vitro. Acta Pharmacol. Sin. 33, 120-126. doi: 10.1038/aps.2011.139

Zhu, H., Ding, W.-J., Wu, R., Weng, Q.-J., Lou, J.-S., Jin, R.-J., et al. (2010). Synergistic anti-cancer activity by the combination of TRAIL/APO-2L and celastrol. Cancer Invest. 28, 23-32. doi: 10.3109/07357900903095664

Conflict of Interest Statement: The authors declare that the research was conducted in the absence of any commercial or financial relationships that could be construed as a potential conflict of interest.

Copyright (c) 2017 Redondo-Blanco, Fernández, Gutiérrez-del-Río, Villar and Lombó. This is an open-access article distributed under the terms of the Creative Commons Attribution License (CC BY). The use, distribution or reproduction in other forums is permitted, provided the original author(s) or licensor are credited and that the original publication in this journal is cited, in accordance with accepted academic practice. No use, distribution or reproduction is permitted which does not comply with these terms. 